\title{
Ambient experience in restitutive treatment of aphasia
}

\author{
Jill S. McClung ${ }^{*}$, Leslie J. Gonzalez Rothi ${ }^{2,3}$ and Stephen E. Nadeau ${ }^{2,3,4}$ \\ 1 Department of Communicative Disorders, Rehabilitation Science, College of Public Health and Health Professions, University of Florida, Gainesville, FL, USA \\ 2 VA RR\&D Brain Rehabilitation Research Center, Malcom Randall DVA Medical Center, University of Florida, Gainesville, FL, USA \\ ${ }^{3}$ Department of Neurology, University of Florida College of Medicine, Gainesville, FL, USA \\ ${ }^{4}$ Neurology Service, University of Florida, Gainesville, FL, USA
}

\section{Edited by:}

Donald T. Stuss, Baycrest Centre for Geriatric Care, Canada

Reviewed by:

William Milberg, Harvard Medical School, USA

Elizabeth Rochon, University of

Toronto, Canada

\section{*Correspondence:}

Jill S. McClung, Department of

Communicative Disorders/

Rehabilitation Science, College of

Public Health and Health Professions,

University of Florida, PO Box 100174,

Gainesville, FL 32610-0174, USA.

e-mail:mcclungj@phhp.ufl.edu
One of the greatest challenges to language rehabilitation is reconciling the fact that the same therapeutic intervention, provided to different individuals with similar types of stroke-induced aphasia, may result in divergent outcomes. In this paper, the authors reviewed existing literature to identify relevant ambient factors - those outside the control of the clinician - that may potentially influence functional language recovery in aphasia and response to treatment. The goal was to develop a clinical history-taking tool to assist clinicians in gathering information germane to each individual's unique circumstances and environment, elements that may have previously been underestimated, to provide a complete inventory of potentially potent prognostic factors. First, two of the authors, speech-language pathologists experienced in aphasia rehabilitation, identified and categorized factors that seemed likely to influence aphasia outcomes. Then, a wide range of literature was reviewed in an effort to identify factors empirically found to be potent influences on aphasia recovery. Where studies relating these factors to aphasia were not found, relevant research from allied fields that examined recovery from brain injury is reported. Moreover, some factors thought to be potentially potent have yet to be examined. Finally, the ambient factors supported by evidence were categorized as facilitators or barriers to functional improvement, and the Ambient Influences on Outcome Checklist (AOC) was developed, including only those factors shown to be potent in the recovery process. It is hoped that this checklist can be used to more broadly assess potential prognostic influences in aphasia restitution, as well as spawn further research.

Keywords: aphasia, language rehabilitation, outcome, ambient experience, therapeutic experience

\section{INTRODUCTION}

Stroke is the leading cause of adult long-term disability worldwide (Whitall, 2004), and aphasia, a potentially debilitating language impairment, affects from 25 to $40 \%$ of stroke survivors. It is estimated that approximately 80,000 persons acquire aphasia every year (National Institute on Deafness and Other Communication Disorders, 2009). Fortunately, some degree of functional recovery from aphasia does occur as a result of both spontaneous brain recovery and therapeutic intervention. However, extrinsic factors beyond spontaneous neural changes and direct therapy, which may be influential in overall restitution of function, have not been defined. In order to maximize language function in aphasia, all factors influencing recovery need to be addressed.

In a paper describing neuroplasticity related to constraintinduced movement therapy (CIMT), Nadeau and Wu (2006) delineate two categories of experience that impact brain and behavior changes during the neurorehabilitative process following brain damage - therapeutic and ambient. These researchers, citing both human and animal studies, suggest that the therapeutic environment consists of clinically based interventions provided and controlled by the rehabilitation professional for purposes of replacing knowledge and skills lost due to neurological insult. In contrast, the ambient environment, i.e., "the daily experience outside of therapy" (Nadeau and Wu, 2006), while also contributing to the replacement of lost knowledge in the brain after infarct, is comprised of factors that are characteristically not controlled by the clinician. It is the authors' contention that both therapeutic and ambient experiences influence functional prognosis in individuals with neurological impairment.

The current paper focuses on identifying potential ambient factors that may be influential in the language recovery of individuals with stroke-induced aphasia through a review of existing literature. It is hoped that this literature review, as well as the Ambient Influences on Outcome Checklist (AOC) that was developed, while not yet tested psychometrically, will both assist evaluators in assessing the potential for recovery of their patients with aphasia, and highlight the crucial need for additional research in the unstudied areas.

\section{BACKGROUND}

Studies of neurorehabilitation and recovery post-stroke focus on two mechanisms - neurobiological processes and experiential processes. Neurobiological processes include the endogenous chemical and physiological processes associated with recovery of neurons from the acute insult, and subsequent neurogenesis and neural migration, axonal sprouting and migration, and synaptogenesis - processes that can be subsumed under the term "reactive plasticity" (Nadeau and Wu, 2006).

Experiential processes, on the other hand, are exogenous processes that induce replacement of knowledge and skills lost due to brain injury. New knowledge and skills are encoded in the brain 
primarily through synaptogenesis and alteration of existing and new synaptic connection strengths. These processes likely recruit normal neural learning mechanisms and may result from combined contributions of therapeutic and ambient experiences. Facilitory experiential processes in humans are analogous to environmental enrichment in animal studies, defined as one or a combination of: (1) enhanced social interaction, (2) increased physical activity, and/or (3) increased learning opportunities (Dahlqvist et al., 2003). These factors in animal studies have been found to increase neurotrophic factors, dendritic branching, number of synapses per bouton, and neurogenesis (Hamm et al., 1996; Johansson and Ohlsson, 1996; Kolb et al., 2000; Risedal et al., 2002; Dahlqvist et al., 2003; Levin, 2003; Johansson, 2004; Milgram et al., 2006; Nadeau and $\mathrm{Wu}, 2006)$. These findings from translational research inform the application of principles of neuroplasticity to humans, with the caveat that there are many factors, most poorly understood, that limit the applicability of animal studies to human subjects with brain injury.

Experiential processes in neurorehabilitation take two forms - therapeutic experience and ambient experience. As previously described, the therapeutic experience for persons with aphasia encompasses direct cognitive-linguistic interventions orchestrated within the clinical environment by the speech-language pathologist. Aphasia intervention, controlled by the clinician, is primarily implemented via task practice. It may be modified by the clinician based on feedback from the patient and/or caregivers, and may also include skill practice beyond the clinic in natural settings to promote generalization. Successful therapeutic experience has been shown to facilitate neuroplastic changes, as illustrated in imaging studies (Adair et al., 2000; Crosson et al., 2005).

Until the current review, ambient experience had been neither defined nor fractionated into factors that may be important in aphasia recovery. The authors define ambient experience as the sum total of characteristically uncontrolled influences on the individual with aphasia, related to severity and recovery potential, that exist outside the clinical environment. This construct may be divided into several functionally useful subcategories (Figure 1).

First, intra-individual factors may be identified, including pre-stroke factors (Threats, 2002), premorbid influences that are not manipulable but may impact post-stroke recovery, and post-stroke factors (Kolb et al., 2000; Worrall, 2006), which may be manipulable. Identified next are extra-individual factors, factors within the individual's environment that influence recovery and

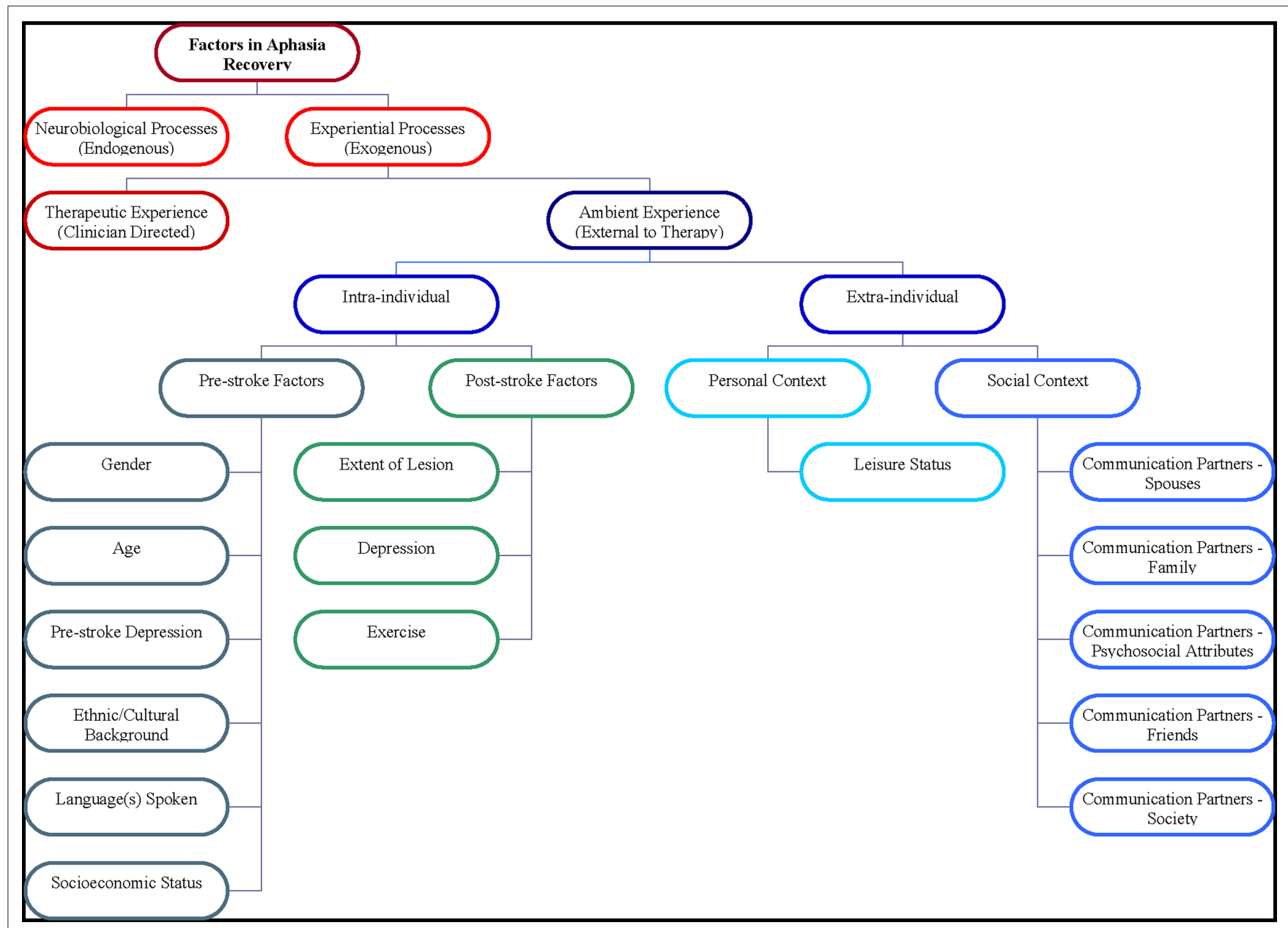

FIGURE 1 | Components of neurorehabilitation in aphasia recovery. 
may or may not be manipulable. These factors include personal context (Wehr et al., 1988; Zeisel et al., 2003; Lorenz, 2007) the individual's environmental surroundings, including levels of physical and cognitive stimulation; and social context - the individual's quality of interactions with family, friends, and other social contacts.

\section{MATERIALS AND METHODS}

First, two licensed speech-language pathologists experienced with aphasia intervention created a list of factors suspected to influence language recovery in aphasia. Once this list was developed, a literature review was conducted via PubMed and Psych Info databases searching a combination of the following keywords: aphasia, severity, environmental enrichment, family, social, leisure, ethnic, education, financial, gender, friend, marital, spouse, work, socioeconomic, environment, caregiver, outcome, employment, religion, spirituality, culture, psychological, coping, and depression. Studies from a diverse range of fields were reviewed, and are specified in Table 1. Factors supported by data, either as a facilitator or a barrier, are highlighted. The remaining factors were not found to have been empirically examined in the journals covered by these search engines. Some factors have been studied within fields other than that of aphasia research, such as nursing or psychology, and others have been studied in relation to stroke in general, without a particular focus on language impairment. It is evident that a number of factors that were considered potentially influential have not been addressed in the literature, and may be important topics of aphasia research. Moreover, the paucity of empirical studies identified necessitated that a qualitative rather than true systematic review be conducted.

Evidence-based factors were organized within a framework that parallels the internationally accepted framework defined by the World Health Organization's (WHO) International Classification of Functioning, Disability and Health (ICF, World Health Organization [WHO], 2001) for classifying factors pertinent to disability. The ICF defines disability as a dynamic interaction between an individual's health condition, for example, aphasia, and contextual factors, either personal [e.g., gender, age, socioeconomic status (SES), coping abilities] or environmental (e.g., social relationships and attitudes, products and technology, physical environment, services; WHO, 2001; Howe et al., 2004). The current paper makes an important contribution to the aphasia rehabilitation literature, as it directly addresses the need, detailed by the Institute of Medicine (2007), to take into account those factors that specifically influence activity limitations and participation restrictions defined by the ICF.

\section{RESULTS}

Presented here is the evidence found to be related to each factor within the framework established for ambient environmental components. The authors attempt to fractionate and clarify these elements in the context of the framework, and conclude by integrating them into a working history-taking tool (Figure 2). At this time, this tool is only meant to serve as a guide for gathering pertinent clinical information, as no attempt has been made to test its validity or reliability. However, future studies to test it in the field are encouraged.

\section{INTRA-INDIVIDUAL FACTORS Pre-stroke factors}

There has been an implicit assumption in the aphasia treatment literature that the most important determinant of language impairment is the extent of damage caused by the stroke (Kertesz et al., 1979; Pedersen et al., 1995; Basso and Caporali, 2001). However, there are a host of other factors that may profoundly influence the pattern of language impairment that occurs, including the resilience of neural knowledge representations in the face of injury; the quality and timing of care in their effects on biological recovery; and the likelihood that a patient with a stroke will end up receiving a rich or poor ambient experience. Pre-stroke factors, to the extent that they modify the neurobiology of the brain and its language faculties, may substantially influence the post-stroke interaction between the subject with aphasia and the ambient and therapeutic environments. Many pre-stroke factors will also persist and more directly influence ambient experience. Pre-stroke factors such as cultural background, education, and SES define the elements that influence the overall spectrum of disability with which stroke patients present separate from ambient and therapeutic experiences. However, several elements within this category, such as gender, age, and pre-stroke depression, significantly influence the ambient experience itself. It is these factors that are discussed first.

Gender. A substantial number of registry-based studies worldwide have demonstrated that women experience greater stroke severity and poorer functional outcomes than men. Large studies in the United States, Europe, Canada, and Scandinavian countries have reported that women may receive fewer medical diagnostic procedures (Gargano et al., 2008) and less thorough medical care (DiCarlo et al., 2003) than men. They are also less likely to be discharged home rather than to a chronic care facility (Glader et al., 2003; Kapral et al., 2005; Gargano et al., 2008), even though they may receive comparable levels of rehabilitation (Holroyd-Leduc et al., 2000). Evidence suggests that women may in fact suffer greater degrees of disability than men following stroke (DiCarlo et al., 2003; Kapral et al., 2005; Lai et al., 2005). For example, they are reported to present with higher incidences of cognitive impairment (Glader et al., 2003), depression (Angeleri et al., 1993; Glader et al., 2002; Eriksson et al., 2004), reduced social activity (Angeleri et al., 1993), inferior physical therapy outcomes (Paolucci et al., 2006), and poorer perception of quality of life (Sturm et al., 2002). Lai et al. (2005) have suggested a possible explanation for this disparity. They postulated that a higher premorbid prevalence of depression and poorer physical function, combined with older age at stroke onset, might explain the reduced mobility and self-care outcomes seen in women.

Likewise, Gargano et al. (2008) identified a number of gender related differences that could be explained by greater age at onset in women compared to men, as well as an increased incidence of urinary tract infections and decreased likelihood of receiving lipidlowering treatment while in the hospital (Gargano et al., 2008). As demonstrated previously by this group (Gargano and Reeves, 2007), women 3 months post onset were less than half as likely to demonstrate recovery of activities of daily living (ADL) than men. More frequent urinary tract infections in women could reasonably be expected to compromise functional recovery; however, the issue of substandard medical intervention has yet to be explained. 
Although the underlying causes remain to be determined, literature supports an advantage of male gender in stroke recovery. Therefore, gender is included in the AOC.

Age. Both animal and human studies of age-related neuroplasticity have found that even though the aged brain exhibits slower neural processes, it is a combination of genetics and individual lifetime experiences that determines the quantity and quality of reorganization possible (Kleim and Jones, 2008). Early studies identified age differences corresponding to the type of aphasia resulting from stroke, such as a mean higher age for fluent (e.g., 56.5 years old) compared to non-fluent aphasia (e.g., 45.3 years old; Brown and Grober, 1983). While some studies of age as a prognostic indicator of aphasia recovery report conflicting results (Code, 2001), most have found an advantage for younger age in the recovery process.

One such study investigated associations between severity of language disorder in chronic aphasia and age (Smith, 1971). A significant relationship was noted between increasing severity and increasing age comparing 36-50 year olds and those over 50 . Likewise, Ross and Wertz (2001) showed that age was directly correlated with language severity, though no correlation was found with overall functional communication measures. These two studies suggest that younger age may be advantageous for recovery of language performance.

A large Scandinavian study, The Copenhagen Stroke Study, examined a more global range of stroke recovery factors, and determined that one of the best predictors of positive functional outcome, including speech and language function, was younger age (Jorgensen et al., 1999). Even in severely disabled stroke survivors, ranging from 60 to 80 years of age, a 10-year age decrease corresponded to a $50 \%$ relative risk reduction for overall poor outcomes, indicating a significant advantage for younger age at onset.

In other stroke studies, age has been found to be significantly related to ADL recovery. Ahlsio et al. (1984) longitudinally examined the influences of emotional and physical disability and quality of life in 96 stroke patients between 35 and 90 years of age. Notable was a significant predictive value of age, as well as initial severity, for overall disability and functional recovery, measured by ADL function 2 years post-stroke. Younger age and less severe impairment were associated with greater physical recovery, most notably in the first 6 months.

In studies of traumatic brain injury, older age has also been determined to lead to less favorable outcomes (Thompson et al., 2006). The predictive value of age on recovery, however, has proven to be differentially related to the type of neurophysiological damage. For example, Levin (2003) found that young age conferred no advantage when the brain injury was severe and diffuse, but was associated with better prognosis for recovery from focal vascular lesions. Levin's study demonstrated that while younger age may be generally advantageous for neurological recovery, age effects may be modulated by lesion characteristics. However, the preponderance of evidence generally suggests that younger age at onset, especially for focal lesions, is advantageous to neural and functional recovery. Thus, age is included in the AOC inventory.

Pre-stroke depression. Evidence has implicated pre-stroke depression as a significant predictor of reduced stroke and aphasia recovery (Williams et al., 2005). This finding has been reported in reviews of risk factors for post-stroke depression, a negative influence on recovery (Provinciali and Coccia, 2002). The factors identified from the literature to be most potent in predicting depression after stroke included family and personal history of depression or other mood disorders, as well as living alone, history of previous stroke, education at high school level or lower, female gender, and life events immediately prior to stroke onset (Provinciali and Coccia, 2002). Because of this empirical support, depression is included in the $\mathrm{AOC}$ as a pre-stroke factor significant in language recovery.

Ethnic/cultural background. Although the study of cultural issues in rehabilitation is relatively new, recent research has examined such factors in the setting of traumatic brain injury. Minority populations in the United States, including Native American Indians, Hispanics, and African Americans, have been demonstrated to be at higher risk for brain injury, as well as for greater severity of consequences, than are Caucasians (Bravata et al., 2005; Arango-Lasprilla and Niemeier, 2007). Researchers have identified ethnic disparities in the time between onset of brain injury and examination by a physician, as well as in the amount of rehabilitation received and resultant functional outcomes, and they have documented a higher likelihood of disability in minority populations. Members of minorities also have been found to have greater difficulty reintegrating into the community and finding employment after brain injury. Cultural differences related to brain injury outcome and process of care have been studied in other countries, such as Australia, in which diverse indigenous cultures have been shown to experience greater difficulties in social integration, return to work, and physical and cognitive independence, separate from SES and accessibility to services (Saltapidas and Ponsford, 2007). Thus, minority populations appear to be at greater risk for reduced rehabilitative outcomes following brain injury, and ethnic/cultural background is included in the AOC inventory.

Language(s) spoken. The strongest determinant of language function post-stroke is the pre-ictal language spoken (Bates et al., 1991b). This is evident in many domains of language function. Two examples are cited here. Perhaps the most dramatic demonstration of the influence of an individual's primary language is in the nature of Broca's aphasia. The prototypic characteristic of Broca's aphasia in English speaking subjects is agrammatism the propensity for omission of both free and bound grammatical morphemes, e.g., articles and auxiliary verbs, and markers of case, number, person and tense. However, in richly inflected languages (almost every major language spoken except English and Chinese) subjects with Broca's aphasia usually retain grammatical morphology, and even the serial order of multiple affixed grammatic morphemes (as in Turkish and Hungarian), and errors far more often involve substitutions - "morphologic paraphasias" (Bates et al., 1991b). Crosslinguistic research has robustly demonstrated that the degree of preservation of grammar comprehension and production in persons with aphasia depends on the relative importance of morphological structures within each person's primary language (Wulfeck et al., 1991).

Dramatic inter-language differences have been noted in other domains of language function. For example, in English, newly introduced concepts are commonly given substantially or completely novel names, whereas in Chinese, there has always been a strong 
propensity for creating names for new concepts by combining old words (e.g., "look-book" for "read") (Bates et al., 1991a). This could have important implications for recovery of lexical impairment in aphasia, the lexicon being as susceptible as it is to age of acquisition effects (Lambon Ralph and Ehsan, 2006). Lexical impairment is the single most common and disabling deficit in aphasia due to stroke (Goodglass, 1993). Thus, the primary language spoken may be considered a powerful ambient factor in the loss and recovery of certain components of language - grammatic morphology and lexical access in the examples given. It is not known, however, whether and to what extent such potential language-specific advantages translate into better recovery of daily communicative ability. Therefore, it is the authors' position that insufficient evidence exists to warrant inclusion of language(s) spoken in the AOC.

Educational level. Evidence from allied health fields has suggested that higher levels of formal educational achievement may buffer the central nervous system from neurological insult (Bennett et al., 2004, 2005). However, studies examining the effects of educational achievement on aphasia recovery have yielded disparate conclusions.

In an early study of 78 individuals with chronic aphasia, Smith reported a significant correlation between higher levels of education, i.e., over 12 years of schooling, and greater residual language function (Smith, 1971). In contrast, a more recent retrospective examination of medical records from 39 unilateral left-sided stroke patients failed to demonstrate a correlation between formal education and aphasia recovery over the course of 103 months, despite an inverse correlation noted between educational level and aphasia severity 4 months post-stroke (Connor et al., 2001). Moreover, Lazar et al. (2007) found aphasia severity 48 months post-stroke to be predicted by initial language impairment rather than education, suggesting that the high degree of variability in individuals with aphasia confounds the assessment of educational effects on either severity or recovery. Likewise, Wertz and colleagues failed to demonstrate a correlation between educational achievement and severity of aphasia, either at onset or 48 weeks post onset, in individuals receiving language intervention (Ross and Wertz, 2001; de Riesthal and Wertz, 2004).

The predictive value of educational background in determining outcomes has been demonstrated in studies of long-term functional disability after stroke (van den Bos et al., 2002) and cognition in individuals with Alzheimer's disease (Bennett et al., 2004, 2005), typically showing a prognostic advantage for higher levels of educational achievement. However, because the evidence specific to aphasia recovery is inconclusive, education has not been included in the AOC.

Socioeconomic status. Although SES has been discussed in a large number of health-related studies, its multidimensional nature has made its status as a predictor of functional recovery from stroke somewhat uncertain. For example, the U.S. generally uses either the number of years of formal schooling or annual taxable income to define SES, whereas Europe typically defines it as occupational class (Jakovljevic et al., 2001; Braveman et al., 2005). Regardless of how SES is defined, however, most studies have concluded that lower SES is associated with an initially greater severity and reduced recovery specific to stroke.
Epidemiological studies have identified correlations between SES, general health, and access to health care (Mortimer and Graves, 1993 in Connor et al., 2001). A review of international research confirmed the association between SES factors and stroke severity (Cox et al., 2006). Two large studies (Jakovljevic et al., 2001; Weir et al., 2005) also demonstrated a direct association between socioeconomic level and functional recovery post-stroke. Jakovljevic et al. (2001), for example, reported significantly greater morbidity and mortality related to low income levels, including longer durations of institutionalization and need of ADL assistance post-stroke. Similarly, in the study by Weir et al. (2005), mortality or dependence at 6 months post onset was correlated with poverty level of neighborhood (Carstairs Census, 1991, in Weir et al., 2005). These results contribute to a recently growing literature that indicates that low income, social, or educational status may increase the risk not only of experiencing a stroke, but also of greater initial severity and ongoing disability for up to 5 years post onset (van den Bos et al., 2002). Thus, SES is included in the inventory.

Handedness. Evidence has been mixed about the prognostic value of handedness in aphasia severity and recovery (Code, 2001). Early researchers hypothesized that left-handed individuals who acquired aphasia would suffer less severe deficits and recover more completely, possibly due to greater bilateral language representation (Luria, 1970, in Basso et al., 1990), and predicted that left-handed individuals were less likely to experience chronic aphasia (Smith, 1971). Two studies of acute aphasia (Gloning et al., 1969; Hecaen and Sauguet, 1971, in Basso et al., 1990) demonstrated that with left-hemisphere lesions, language performance was similar in right- and left-handed individuals, but left-handed patients showed more severe language deficits if they had experienced a right-sided lesion.

However, in studies that have specifically examined the influence of strong left-hand preference, no relationships have been found between handedness and functional hemispheric organization (Hecaen and Sauguet, 1971, in Basso et al., 1990), or side of stroke and functional aphasia recovery (Holland et al., 1989). In a sample of 186 patients with aphasia, Code and Rowley (1987, in Code, 2001) found no relationship between handedness and aphasia type. In addition, Basso et al. (1990), in a well-controlled study of 90 individuals with left-hemisphere stroke and aphasia, found no significant differences in language recovery following 5 months of speech therapy. These studies suggested that lefthanded persons with aphasia resulting from a left-hemisphere lesion had no better prognosis than right-handed individuals. Later, a very large aphasia study comparing language function from acute onset to time of discharge and 6 months following discharge, also failed to find a significant effect of handedness on recovery (Pedersen et al., 1995). Based on this body of research, handedness has not been included in the AOC as an ambient factor.

Pre-ictal brain organization. Every clinician has observed variability in the degree to which different patients with seemingly identical lesions recover language function. At times this may be quite dramatic: right-handed patients with very large left hemisphere strokes recover normal or nearly normal language function, in some 
cases only to experience recurrent aphasia with a right brain lesion (Nadeau and Gonzalez-Rothi, 1993). Such cases clearly demonstrate a substantial range in the inter-hemispheric distribution of the substrate for language function. For the most part, the mechanisms underlying this variability are not known. It is clear, as noted above, that premorbid language has an influence. Grammatic morphology tends to be much better preserved after left hemisphere stroke in patients speaking richly inflected languages (Bates et al., 1991b). There is also indirect evidence of language ontogenesis throughout the life span, witness the previously noted higher prevalence of Wernicke's aphasia in older patients with stroke (but also with brain tumors and traumatic brain injury) (Brown and Grober, 1983). Although pre-ictal organization of language function may be one of the most powerful predictors of recovery of language function after stroke, we have not included it in the AOC because of our lack of understanding of the mechanisms involved and lack of measures tapping these mechanisms.

Genetic and epigenetic influences. Heterozygous mutations of the FOXP2 gene have been identified as a cause of specific language impairment (SLI), a rare Mendelian inherited speech and language disorder (Vernes et al., 2008). FOXP2 encodes a transcription factor that regulates the expression of a number of genes. Significant quantitative associations have been demonstrated in families with probands afflicted by SLI between single nucleotide polymorphisms in one of these regulated genes, CNTNAP2, and non-word repetition, a robust endophenotype of SLI (Vernes et al., 2008). CNTNAP2 is differentially expressed during human ontogenesis in the middle and inferior frontal gyri (Abrahams et al., 2007). It may mediate intercellular interactions during neuroblast migration and laminar organization of the brain during cortical development (Strauss et al., 2006). Because mutations in these various genes cause inherited disorders of language function, it seems highly likely that other genes influence the intra- and inter-hemispheric distribution of the substrate for language function, as well as other factors related to the recovery of language function after stroke.

Recovery of language function after stroke is also almost certainly affected by genetic factors influencing neuroplasticity. For example, neuroplasticity appears to be reduced in subjects with the val66met polymorphism in brain derived neurotrophic factor, compared with subjects with the val66val and met66met polymorphisms (Kleim et al., 2006).

Epigenetic factors may exert as yet undetermined influences. Epigenetics involves modulation of gene expression. The pattern of gene expression not only evolves through the lifetime, but it may, to some degree, be inherited, thereby instantiating a neoLamarckian version of evolution. The potential power of epigenetic influences should not be underestimated. They are, for example, responsible for the metamorphosis of caterpillar into pupa and ultimately, butterfly.

Although genetic and epigenetic factors are likely to have a profound influence on the development of and recovery from aphasia after stroke, and although almost certainly we will 1 day discover ways of manipulating them, because so little is understood about them at this time, they have not been included in the AOC.

\section{Post-stroke factors}

Extent of lesion. With very few exceptions, researchers have demonstrated that lesion site and size are critical factors in determining recovery from aphasia (Lendrem and Lincoln, 1985; Mark et al., 1992 in Lazar, 2007; Kertesz, 1988 in Lazar et al., 2007). In a review of recovery mechanisms in stroke and aphasia patients, Rijntjes (2006) concluded that lesion localization is crucial to neural reorganization. Moreover, Stineman and Granger (1998) and Pedersen et al. (1995) are among numerous researchers who have demonstrated that the initial extent of the infarct is an essential, and perhaps the primary, predictor of recovery. Thus, the extent and location of the lesion are included as potent ambient factors in the checklist.

Depression. Researchers have demonstrated that psychosocial adjustment and emotional state post-stroke constitute critically important influences in recovery (Code and Muller, 1992 in Code, 2001; Eslinger et al., 2002). Depression has been associated with both increased mortality and morbidity (Ramasubbu and Patten, 2003). Moreover, depression, functional abilities, and social support have been shown to be the three primary predictors of quality of life in stroke survivors (King, 1996), depression being perhaps the most potent in determining the severity of the disability (Kwok et al., 2006; Lo et al., 2008). Patient reports of quality of life before and after stroke have demonstrated that they consider depression and anxiety every bit as important as physical disability, and this perspective persists even when ADL have substantially improved (Ahlsio et al., 1984).

There is a higher likelihood of depression after stroke when the person experiences aphasia (Damecour and Caplan, 1991, in Provinciali and Coccia, 2002). In addition, stroke with depression leads to increased prevalence of institutionalization, poorer rehabilitation outcomes, and increased hospital length of stay (Provinciali and Coccia, 2002; Meijer et al., 2005). Risk factors for depression and time post onset have been reported to interact. For example, in the acute phase, language impairment and living alone have been found to be most predictive of depression, whereas at 3 months, self-care disability is most important, and at two to 3 years, reduced social contacts predict depression best (Provinciali and Coccia, 2002).

Successful treatment of depression in stroke survivors improves both mood and functional outcomes (Eslinger et al., 2002). For example, Robinson et al. (2000) conducted a double-blind placebo-controlled study of nortriptyline and fluoxetine in treatment of depression in stroke patients in which they measured functional change. Nortriptyline was found to be more efficacious in improving not only depression and anxiety, but also the ability to perform ADL. Individuals with post-stroke depression are also reported to demonstrate greater cognitive impairment, especially after left hemisphere stroke, and successful treatment of depression resulted in a significantly greater cognitive recovery (Kimura et al., 2000). In fact, effective treatment of post-stroke depression has been shown to significantly improve both physical and cognitive outcomes (Gonzalez-Torrecillas et al., 1995). The conclusion that depression directly influences functional outcomes highlights the critical nature of addressing depression in individuals 
with aphasia and making appropriate referrals as indicated. Thus, based on the evidence, it has been included as a potent prognostic factor in the AOC.

Expectations. The potential impact of patient and caregiver expectations on stroke recovery has been discussed by a number of researchers (Jeffreys, 2001; Bluvol and Ford-Gilboe, 2004; McKevitt et al., 2004; Duncan et al., 2005; Redfern et al., 2006). However, no empirical studies of this factor's impact on stroke or aphasia recovery were identified. Therefore, it has not been included in the AOC.

Time post onset. Whether or not language therapy is provided for aphasia is not a proposed factor in this review. However, the time following stroke onset at which treatment is initiated is considered an ambient factor. Neural reorganization following acute stroke occurs in a sequential pattern, based on clinical and translational studies (Rijntjes, 2006; Cramer, 2008), and the greatest gains in function occur primarily within the first 3 months poststroke onset. Beyond 3 months, function continues to increase, but a higher probability of spontaneous improvement exists for cognitive compared with motor abilities (Cramer, 2008). Neural changes appear to occur in epochs, whereby the greatest potential may occur within the first several weeks following infarct (Cramer, 2008). However, evidence suggests that the initiation of restorative intervention may be effective any time after the first several days of acute changes, and may be facilitory even several years after stroke onset (Cramer, 2008).

Therefore, controversy still exists as to the ideal time after stroke and the intensity of therapeutic intervention that will produce optimal functional recovery. It may be that time post onset becomes less influential past a certain period in the recovery process, as suggested in a study of individuals with aphasia by Moss and Nicholas (2006). They showed that the time at which intervention was initiated did not correlate with the magnitude of improvement once the subjects were beyond 1 year post onset (Moss and Nicholas, 2006). In an early study of language performance outcomes following treatment of individuals with aphasia during the first year post-stroke, differential recovery rates were identified based on type of aphasia. Sarno and Levita (1979) demonstrated that persons with fluent aphasia exhibited the greatest gains in the first 6 months and few gains thereafter, whereas individuals with global aphasia showed the opposite pattern. Other studies, however, have failed to identify a significant effect of time post onset of therapy initiation on cognitive-linguistic recovery (Hochstenbach et al., 1998, 2003). Similarly, studies of cerebral blood flow changes associated with language recovery in persons with aphasia have been inconclusive (Mimura et al., 1998).

In a meta-analysis of 21 studies examining treatment effects in aphasia rehabilitation, Robey reported that when speech-language therapy was implemented within the first 4 months following stroke, therapeutic gains were nearly twice as large as when treatment occurred after 4 months (Robey, 1994; see also Robey, 1998). However, it is very difficult to separate effects of language therapy from effects of spontaneous recovery processes during this early period. On the other hand, significant therapeutic benefits have also been demonstrated in later stages following stroke onset
(Meinzer et al., 2004), as confirmed by a recent review of the efficacy of aphasia treatment in chronic stages that revealed significant functional improvements (Raymer et al., 2008). It is clear that the time at which an individual receives treatment for aphasia is influential to language recovery, but much more research is needed to determine optimal timing. Therefore, time post onset has not been included in the checklist.

Exercise. Although no studies were found relating exercise specifically to aphasia outcomes, many have examined its effects on brain function in healthy young and older adults, persons with respiratory disorders, individuals with Alzheimer's disease, and persons with depression. A number of papers have investigated neurophysiological changes that have resulted from augmented aerobic, but not non-aerobic, physical fitness. For example, in older adults, aerobic interventions have resulted in increased white matter integrity (Marks et al., 2007), as well as greater frontal and temporal brain volumes (Colcombe et al., 2006). In younger adults, increases in the neurochemicals involved in learning have been identified immediately following high impact exercise, with concurrent increases in learning and retention (Winter et al., 2007). Colcombe and Kramer (2003) conducted a meta-analysis of 18 studies examining the effects of aerobic exercise on cognition in sedentary older adults. They concluded that fitness training significantly improved performance on all cognitive tasks, particularly tasks of executive function. Likewise, Netz et al. (2007) reported immediate and significant increases in cognitive flexibility after only one 44-min treadmill session.

A number of prospective cohort studies have shown an association between greater physical activity at baseline and attenuated rate of cognitive decline or reduced incidence of dementia in subsequent years (Lautenschlager et al., 2008). Lautenschlager et al. (2008) conducted a randomized controlled trial of a 24 -week exercise program in elderly subjects. They found that exercise was associated with improvement in cognitive function as measured by the Alzheimer's Disease Assessment Scale-Cognitive, while cognitive function declined in the control group. Arkin conducted a 4-year holistic intervention incorporating exercise, cognitive stimulation, and social interactions, and found that the overall program slowed cognitive decline in most of the subjects (Arkin, 1999, 2003). At present, the National Institutes of Health are funding a number of studies testing the effects of aerobic exercise on cognition in healthy seniors and in individuals with mild cognitive impairment, traumatic brain injury, and dementia (National Institutes of Health, 2008). These findings suggest that while aphasia-specific research is crucial, aerobic exercise may be a potentially influential factor in aphasia recovery, as well, and thus, it is included in the AOC.

Spirituality. Despite an implicit acknowledgement in the literature of the importance of spirituality on health outcomes, few empirical studies were identified. The authors found no studies examining the effects of spirituality on aphasia recovery, and only a limited number investigating it in other health contexts that reported data collection and analysis. A large study of men with HIV/AIDS examined spirituality self-ratings in relation to the efficacy of counseling interventions (Frame et al., 2005). The results revealed that in this population, spiritual coping was not 
associated with health-related quality of life. Participants' expression of spiritual growth reportedly improved certain aspects of their emotional state but did not facilitate physical well-being or reduce the perception of pain.

On the other hand, several sociological studies of healthy older adults have demonstrated positive links between faith-based activities and quality of life. Idler (1987), in a study of over 2000 elders, found that higher levels of involvement in organized religious activities were associated with reduced levels of depression and functional disability. Similarly, Ellison (1991) showed a strong association between self-rated faith and quality of life, especially when coping with traumatic life events. It seems likely that spirituality exerts different influences based on the nature and etiology of an individual's disability. These findings suggest that spirituality may be an important factor in stroke recovery and in the impact of ambient experience on aphasia recovery. However, since research specific to aphasia was not identified, spirituality is not listed in the AOC.

\section{EXTRA-INDIVIDUAL FACTORS Personal context}

Physical living environment. Some healthcare literature has examined the effects of physical environment on several patient populations, particularly individuals with dementia, though none has addressed persons with aphasia. Certain environmental features, including architectural design, are strongly associated with vital health and behavioral outcomes in individuals with Alzheimer's disease (Zeisel et al., 2003; Wood et al., 2005). Ample light, minimal background noise, clearly labeled rooms, and home-like ambiance have been shown to maximize cognitive functioning and decrease disruptive behaviors in this population (Brush, 2007). Similarly, studies examining affective disorders have reported significant environmental influences such as these on psychological function (Wehr et al., 1988).

Studies of environmental factors related to the recovery of ill individuals in hospitals and other institutional settings have been reported in the nursing literature. Lorenz (2007), for example, conducted an integrative review of 16 quantitative and two qualitative studies from the fields of medicine, architecture, psychiatry, and environmental psychology to define what she calls "the healing environment," empirically demonstrated to impact recovery of physical and mental health. These studies examined clinical outcomes, patient perceptions, and hospital employee perceptions based on such influences as brightness and design of patient rooms, types and levels of noise in the critical care environment, view from room, and levels of social isolation. Patient outcome measures included length of stay, evaluation of staff, physiological reactions such as heart rate, and anxiety and depression measures. The review identified five evidence-based factors that might promote positive therapeutic outcomes if integrated into health care environments psychologically supportive surroundings, enhanced patients' sense of control, social support, positive distractions, and reduced negative distractions (Lorenz, 2007).

One study that targeted physical environmental influences on the abilities of stroke patients was located (Harrison et al., 2003). Ambient sensory conditions, such as light and sound, had been manipulated in previous studies with elders and children, and resulted in changes in cognitive function. These researchers reported that bright light measurably improved speech detection in a dichotic listening test in a sample of ten stroke patients (Harrison et al., 2003). This evidence suggests that environmental influences may be instrumental in the healing process, but specific environmental barriers and facilitators for reduction of aphasia will require further study. Thus, it is not included in the AOC.

Occupational status. Although a number of studies examined vocational outcomes following stroke, none reported on aphasia recovery. Neau et al. (1998) assessed return to work, post-stroke depression, and quality of life 1 year after stroke in younger adults, and found that only half returned to their previous work. Furthermore, depression was strongly associated with the inability to return to work, as well as the severity of disability and reports of quality of life. It seems probable that occupational status poststroke may be a powerful factor in the recovery process, based on its effect on life satisfaction in healthy individuals (Melin et al., 2003), but it is not included in the AOC checklist because further analysis is essential to support this assumption.

Leisure status. A number of studies have examined the relationship between life satisfaction and level of participation in daily activities following stroke. Most have demonstrated that involvement in leisure activities, an element of instrumental ADL (IADL), contributes significantly to reports of well-being. For instance, Hartman-Maeir et al. (2007) examined this relationship in 56 home-dwelling stroke patients in Israel 1 year post-stroke. These researchers examined how functional activity limitations and participation restrictions, measured by basic and instrumental ADL scales, employment and leisure involvement, and depression, impacted overall life satisfaction. They reported that life satisfaction correlated more strongly with participation level, reflected in IADL and recreational activities, than with functional independence, measured by basic ADL level. A significant correlation was also found between depression and life satisfaction.

Similar conclusions were reported in a Norwegian study that examined the relationship between subjective well-being and IADL independence (Sveen et al., 2004). In a sample of 64 stroke patients evaluated at 6 months post-stroke, these authors found that leisure involvement was significantly associated with life satisfaction. Thus, involvement in leisure activities may be important in reducing social isolation, and possibly even mitigating declines in overall health. Therefore, leisure activity involvement is included in the AOC inventory.

\section{Social context}

Communication partners - spouses. Marital status has been shown to be predictive of the location to which individuals are discharged 6-12 months following stroke (Meijer et al., 2004). Individuals who do not live alone, as well as those who have a supportive social network, are more likely to be discharged home (Pedersen et al., 1995; Brosseau et al., 1996; Jorgensen et al., 1999). In fact, discharge location is often used as an outcome measure for assessing stroke recovery (Niemi et al., 1988). 
That one has a spouse has recently been shown to be instrumental in enriching or diminishing the recovery process in persons with aphasia. In studying communication interchanges between stroke survivors and spouses, Blonder (Blonder, 2000) distinguishes between language competence, the ability to use the rules of language, and communicative competence, the ability to spontaneously communicate in a socially interactive context. The few studies that have examined interactive communication in individuals with aphasia have demonstrated that these patients may retain, through relatively preserved discourse and pragmatic strategies, their communicative effectiveness in the real world, despite severe linguistic impairments (Glosser and Deser, 1991). Studies have shown that this conversational competence is actually reliant on behaviors not only by the persons with aphasia, but also by their communication partners, who may either help or hinder communicative competence. Caregivers may facilitate conversation if they use strategies to repair both actual and perceived errors within the discourse context (Milroy and Perkins, 1992; Perkins, 1995) or, alternatively, they may pose barriers. Burns et al. (1991) reported a case in which the wife of a gentleman with aphasia helped to maximize his communicative competence by paraphrasing and simplifying the researcher's inquiries, illustrating the importance of collaborative efforts by both parties to enable functional communication. On the other hand, spouses may exert detrimental effects on the conversational effectiveness of individuals with stroke, either with or without aphasia. Spouses have been found to correct patients, question their accuracy, and even compete with them, resulting in demonstrations of loss of control by the individuals with stroke (Manzo et al., 1995). This type of negative interaction may exert profound effects on the social relationships of the stroke survivor, which in turn may lead to reduced self-esteem and social isolation. Therefore, psychosocial dysfunction may be a direct result of impairments in communicative competence, even within the affected individual's own family (Blonder, 2000). Subsequently, aphasia may significantly alter a patient's role within the family structure. Patients may lose prior leadership roles, reliant upon extensive verbal communication, and become relatively passive, uncommunicative participants in activities defined by others (Blonder, 2000). To summarize, spousal partners and their interactions with individuals with aphasia exert potent influences on functional restitution, and therefore this factor is included in the AOC.

Communication partners - family. Three predictors of quality of life in individuals between 1 and 3 years post-stroke - social support, depression and functional ability - have been noted by King (1996). A considerable number of studies have provided evidence that the social context within the family unit in general has a dramatic impact on recovery and quality of life of persons with aphasia, and that positive social and emotional support from family is crucial for positive outcomes (Glass et al., 1993; Tsouna-Hadjis et al., 2000; Ouimet et al., 2001; Eslinger et al., 2002; Meijer et al., 2004). Glass et al. (1993) demonstrated a $65 \%$ increase in patients' function on the Barthel Index when family support was positive. They also determined that social isolation was a risk factor for a poor prognosis. Similarly, Duncan et al. (2005), in a summary of the Department of Veterans
Affairs recommendations for stroke care, cited several studies that associated positive family caregiver support with improved patient outcomes. The level of emotional support from family significantly correlates with the patient's functional status, depression, and social competence (Tsouna-Hadjis et al., 2000), and high levels of social support have been shown to result in more expeditious and extensive functional recovery in stroke patients (Glass et al., 1993; TsounaHadjis et al., 2000), making family support a significant ambient factor included in the AOC.

Communication partners - psychosocial attributes. Several aphasiaspecific studies have investigated spousal perceptions of their partners with aphasia. Croteau and LeDorze (2001) reported significantly different attitudes in spouses of individuals with aphasia versus controls on scales of likeability, achievement, and endurance. Interestingly, gender differences emerged as well, reflecting that wives rated their husbands with aphasia lower in achievement and endurance, compared with husbands of women with aphasia. Similarly, Zraick and Boone (1991) found that spouses of persons with aphasia, especially non-fluent aphasia, expressed more negative attitudes toward their spouses when compared to controls. Considering how important the caregiver relationship has been shown to be in aphasia recovery, these studies suggest that individuals with aphasia and their spouses might benefit from educational and psychological support measures. In fact, several interventions targeted at educating and providing psychosocial support to caregivers of stroke patients have shown promise in improving the stroke survivors' recovery (Evans et al., 1988).

The interdependence of stroke patients' recovery and their caregivers' attitudes has also been studied recently, highlighting the importance of caregivers' psychological status to the patient's recovery. One study used structural equation modeling to examine the relationships between caregivers' psychosocial functions and their care recipients' abilities, including language function (Perrin et al., 2008). The authors reported a profound impact of caregivers' feelings of competence, depression, and coping skills on their care recipients' emotional states, cognitive functions, and life participation. Similarly, a study conducted by Barskova and Wilz (2007) assessed physical and mental functional recovery of 81 stroke patients, along with their caregivers' health and attitudes, at hospital discharge and 1 year post-stroke. Greater levels of ADL dependence resulted in caregivers' depression and reduced wellbeing. In turn, caregivers' self-reported psychosomatic complaints were strongly negatively correlated with their partner's cognitive competence, which subsequently impacted caregiver acceptance of the partners' new life roles.

Finally, Low et al. (1999) reported that caregiver feelings of burden and incompetence adversely affect the care of stroke patients, as well as elders. Family members' self-assurance in skill proficiency, facilitated by professional health care support, is important for caregivers to be able to render proper care (Greenberger and Litwin, 2003), and depression in caregivers, even prior to the onset of the individual's illness, may result in a reduction in time spent caring for the person at home, in disabled elders and stroke patients (Arai et al., 2001; Cameron et al., 2006). Because psychosocial attributes of communication partners likely affect patient outcomes (Bates et al., 2005), this ambient factor is included in the AOC. 
Communication partners - friends. A number of studies have examined the importance of social interaction in the recovery of language function and psychosocial well-being in individuals with aphasia (Hopper et al., 2002; Elman, 2007). These studies reflect the ICF model's emphasis on participation as a rehabilitation outcome, and the authors have suggested that group aphasia treatment may be as effective as individualized treatment (Wertz et al., 1981, in Elman, 2007) because of its stimulation of functional conversation. An outgrowth of this philosophy is the recent development of aphasia centers and support groups, which facilitate socialization as a crucial component in language recovery (Elman, 2007). Hilari and Northcott (2006) report that nearly 30\% of individuals with chronic aphasia declare that they have no friends, and those who do have friends report significantly fewer than their age-matched peers (Cruice et al., 2006).

Satisfaction with social support received from friends has been identified as a significant predictor of quality of life by individuals with chronic aphasia (Ross and Wertz, 2003; Hilari and Northcott, 2006; Elman, 2007). A close social network may decrease social isolation, reduce depression and, as a result, facilitate functional recovery (Davidson et al., 2008). People with aphasia report social isolation as their primary problem (Sarno, 1997). Close friends may be as integral in serving as communication partners as are relatives (Sacchett et al., 1999; Cruice et al., 2005), and may even be more crucial than family to health-related quality of life (Hilari and Northcott, 2006) and emotional well-being (Davidson et al., 2008). Their importance may be related to the fact that they are able to provide emotional and informational support without a sense of familial obligation (Hilari and Northcott, 2006). Thus, the impact of friendship relationships is included in the AOC as a potent variable in aphasia recovery.

Communication partners - society. Societal effects on the functioning of persons with aphasia have been extensively studied since the adoption of the ICF model by the American Speech-Language Hearing Association (ASHA) in 2001. The ability to access information, health care services, and transportation has been found to strongly impact the quality of life reported by individuals with chronic aphasia (Ross and Wertz, 2003). Howe et al. (2007) qualitatively observed 10 individuals with aphasia as they interacted in a variety of community situations, during which they identified three principal categories of barriers and facilitators to communication - person-driven, physical, and societal. Examples of barriers that were identified included unaccommodating attitudes by service providers, such as speaking too quickly to allow comprehension, confusingly organized bus schedules, and written application forms that fail to contain explicit instructions to aid individuals with communication deficits. In contrast, facilitators included sales persons who explained instructions clearly, easily accessible information pamphlets, and special ticket purchase accommodations for individuals with language disorders.

A review of influential environmental factors conducted by the same group (Howe et al., 2004) concluded with the authors' explicitly defining aphasia-friendly environments. Based on the ICF model, environmental factors include all external influences on the individual, including societal attitudes and physical environment, and personal social relationships with family and friends.
Barriers to communicative competence of persons with aphasia include background noise, increased rate of speech by communication partners, exclusion from conversations, and restrictions from social services (Parr et al., 1997; Parr and Byng, 2000). In order to eliminate these barriers, society can be educated regarding what constitutes an aphasia-friendly environment, how to modify speech complexity, and the importance of including persons with aphasia in social services (Parr et al., 1997). These facilitators may also be extended to the employment environment (Garcia et al., 2000), and communication partners, as has been demonstrated in studies by Kagan et al., (2001), Rayner and Marshall (2003), and Simmons-Mackie et al. (2007). Aphasia-specific barriers and facilitators have also been identified by service industry employees themselves (Brown et al., 2006). As is reflected in the rapidly burgeoning literature in this field of study, the impact of society on aphasia restitution is clearly a potent factor, and is included in the AOC inventory.

Health care professionals. Although health care professionals provide interventions that by definition are within the context of therapeutic experience, the interpersonal relationships that they have with patients also play an important ambient experience role in facilitating recovery in patients with stroke and aphasia. Boylstein et al. (2005) investigated the mechanisms underlying the efficacy of constraint-induced motor therapy (CIMT) in physical restitution, and demonstrated that an essential component of this intensive treatment is a collaborative interaction between therapist and patient. Likewise, Worrall (2006) analyzed interactions between speech-language pathologists and their patients, and demonstrated that many of these relationships centered on the goals of the therapist rather than the patient, having a potentially negative impact on therapy outcomes. She concluded that therapy needs to be person-centered, with clinicians promoting patient-directed goals, facilitating functional involvement in activities and relationships, and nurturing self-esteem and decision-making independence in order to maximize recovery. However, based on the need for empirical support in this area, this factor has not been included in the AOC.

\section{THE CHECKLIST}

The authors have incorporated the empirically supported factors just discussed (Table 1) into a user-friendly clinical guide, the AOC (Figure 2). It is intended to be employed as part of the clinician's history-taking process, an adjunct to prognostic assessment, and should be tested for validity and reliability in future studies. It is hoped that it will help enrich and optimize the course of language intervention promoting aphasia recovery, coalescing therapeutic and ambient experience to achieve functional transfer - generalization - of communicative competence.

\section{GENERALIZATION}

The ultimate goal for patients with aphasia is to attain maximal functional recovery based on the contextual synthesis of both therapeutic and ambient experiences. In order to achieve this goal, every therapeutic gain must be generalized to the everyday living environment. There has been essentially no systematic research on mechanisms of generalization, but a number have been postulated (Nadeau et al., 
Table 1 | References for Ambient Factors

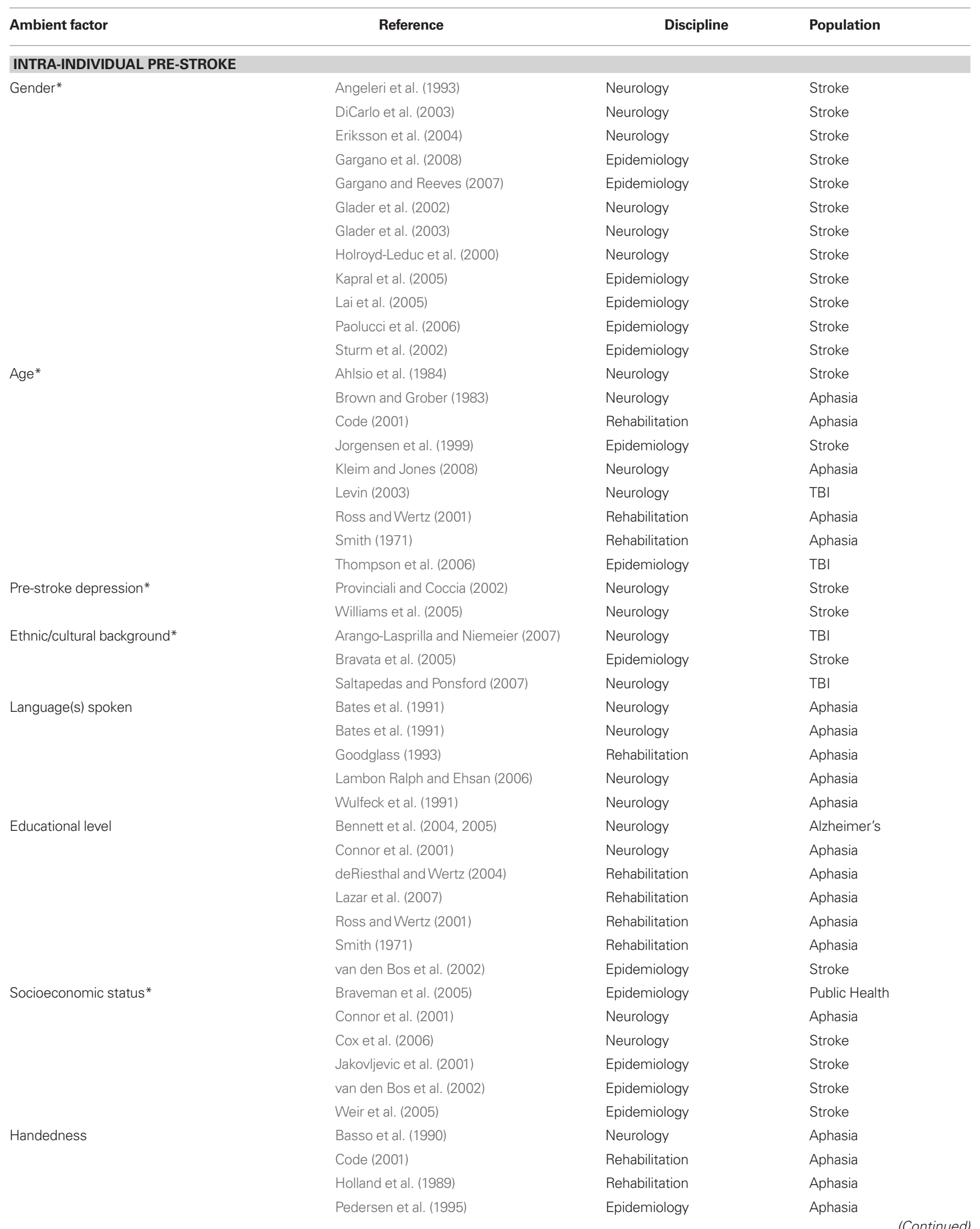


Table 1 | References for Ambient Factors

\begin{tabular}{|c|c|c|c|}
\hline Ambient factor & Reference & Discipline & Population \\
\hline & Smith (1971) & Rehabilitation & Aphasia \\
\hline \multirow[t]{3}{*}{ Pre-ictal brain organization } & Bates et al. (1991) & Neurology & Aphasia \\
\hline & Brown et al. (1983) & Neurology & Aphasia \\
\hline & Nadeau and Gonzalez-Rothi (1993) & Neurology & Aphasia \\
\hline \multirow[t]{3}{*}{ Genetic and epigenetic influences } & Abrahams et al. (2007) & Neurogenetics & Tissue \\
\hline & Strauss et al. (2006) & Neurogenetics & Epilepsy \\
\hline & Vernes et al. (2008) & Genetics & Specific Lang. Impairment \\
\hline \multicolumn{4}{|l|}{ POST-STROKE } \\
\hline \multirow[t]{2}{*}{ Extent of lesion* } & Lazar et al. (2007) & Rehabilitation & Aphasia \\
\hline & Lendrem and Lincoln (1985) & Rehabilitation & Aphasia \\
\hline \multirow[t]{10}{*}{ Depression* } & Ahlsio et al. (1984) & Neurology & Stroke \\
\hline & Code (2001) & Rehabilitation & Aphasia \\
\hline & Eslinger et al. (2002) & Psychology & Stroke \\
\hline & Gonzalez-Torrecillas et al. (1995) & Psychiatry & Stroke \\
\hline & Kimura et al. (2000) & Psychiatry & Stroke \\
\hline & King (1996) & Psychology & Stroke \\
\hline & Kwok et al. (2007) & Rehabilitation & Stroke \\
\hline & Lo et al. (2008) & Rehabilitation & Stroke \\
\hline & Meijer et al. (2005) & Rehabilitation & Stroke \\
\hline & Provinciali et al. (2002) & Neurology & Stroke \\
\hline \multirow{2}{*}{ Expectations } & McKevitt et al. (2004) & Neurology & Stroke \\
\hline & Redfern et al. (2006) & Neurology & Stroke \\
\hline \multirow[t]{10}{*}{ Time post onset } & Cramer (2008) & Neurology & Stroke \\
\hline & Hochstenbach et al. (2003) & Rehabilitation & Stroke \\
\hline & Hochstenbach et al. (1998) & Rehabilitation & Stroke \\
\hline & Meinzer et al. (2004) & Psychology & Aphasia \\
\hline & Mimura et al. (1998) & Rehabilitation & Aphasia \\
\hline & Moss and Nicholas (2006) & Neurology & Aphasia \\
\hline & Raymer et al. (2008) & Neurology & Aphasia \\
\hline & Rijntjes (2006) & Neurology & Aphasia \\
\hline & Robey $(1994,1998)$ & Rehabilitation & Aphasia \\
\hline & Sarno and Levita (1979) & Rehabilitation & Aphasia \\
\hline \multirow[t]{6}{*}{ Exercise* } & Arkin $(1999,2003)$ & Rehabilitation & Alzheimer's \\
\hline & Clinicaltrials.gov website & Research & Elders \\
\hline & Colcombe and Kramer (2003) & Psychology & Elders \\
\hline & Colcombe et al. (2006) & Psychology & Elders \\
\hline & Marks et al. (2007) & Aging & Elders \\
\hline & Netz et al. (2007) & Physiotherapy & Middle aged \\
\hline
\end{tabular}


Table 1 | References for Ambient Factors

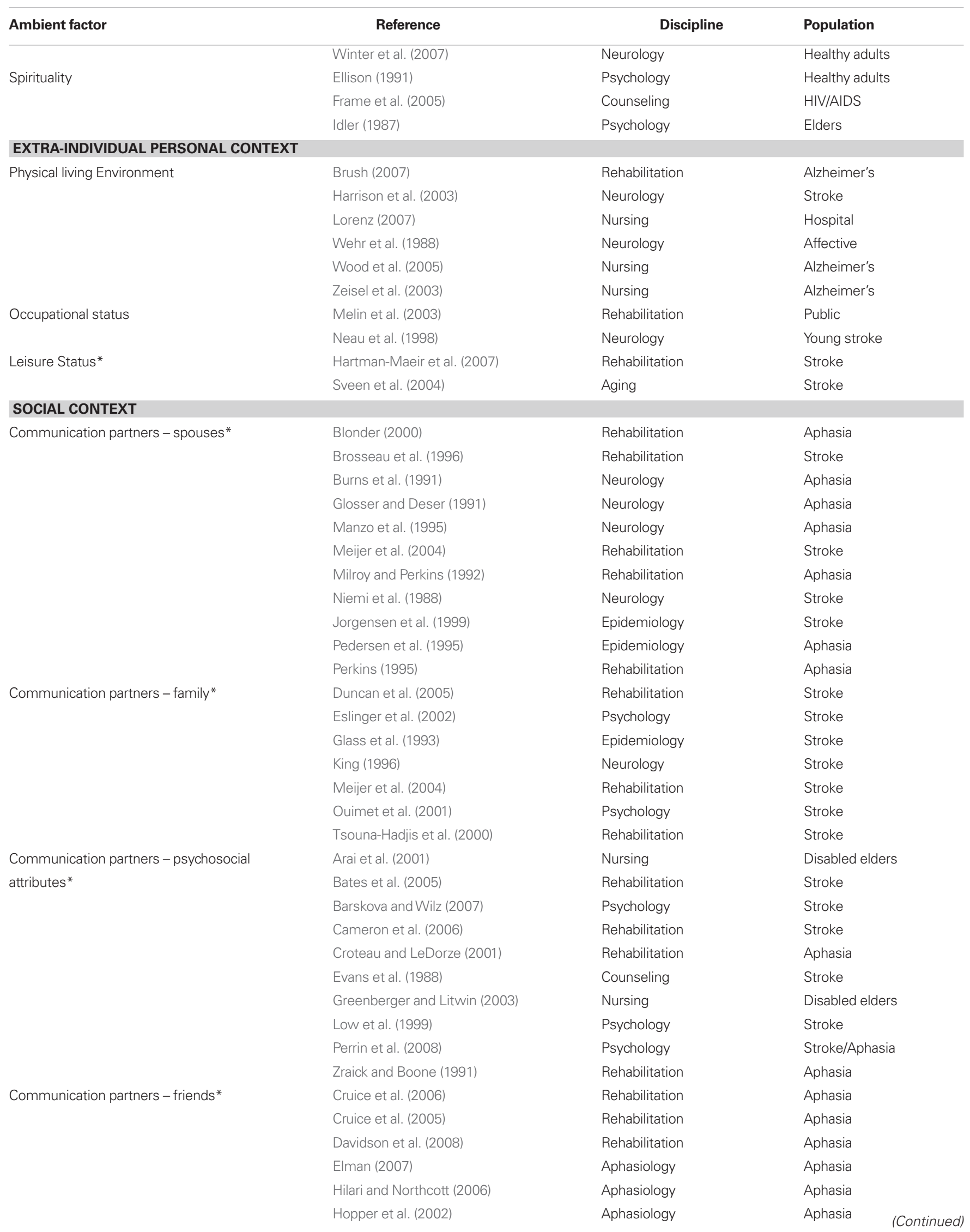




\begin{tabular}{|c|c|c|c|}
\hline Ambient factor & Reference & Discipline & Population \\
\hline & Ross et al. (2003) & Rehabilitation & Aphasia \\
\hline & Sacchett et al. (1999) & Rehabilitation & Aphasia \\
\hline & Sarno (1997) & Aphasiology & Aphasia \\
\hline \multirow[t]{7}{*}{ Communication partners - society* } & Brown et al. (2006) & Rehabilitation & Aphasia \\
\hline & Garcia et al. (2000) & Rehabilitation & Aphasia \\
\hline & Howe et al. (2007) & Rehabilitation & Aphasia \\
\hline & Kagan et al. (2001) & Rehabilitation & Aphasia \\
\hline & Parr, et al. (1997) & Rehabilitation & Aphasia \\
\hline & Parr and Byng (2000) & Rehabilitation & Aphasia \\
\hline & Ross et al. (2003) & Rehabilitation & Aphasia \\
\hline Health care professionals & Worrall (2006) & Rehabilitation & Aphasia \\
\hline
\end{tabular}

*Supported by data.

2008). Some mechanisms of generalization are related to the linguistic substance of the therapeutic experience. For example, Intrinsic generalization involves the application of knowledge acquired in therapy (e.g., semantic features, phonological sequences, phonetic sounds, syntactic techniques) to other knowledge that shares these features or sequences, or to situations that allow application of the acquired techniques. Cross Function generalization involves the development of knowledge during therapy that can be applied to multiple tasks. For example, semantic therapy could benefit oral word production, written word production, oral word comprehension, and written word comprehension because all four capacities involve networks linked to association cortices supporting concept representations. However, the four mechanisms of generalization discussed below involve implicit, explicit, or potential fusions of therapeutic and ambient experience.

Extrinsic generalization involves the development during therapy of a knowledge acquisition or skill learning technique that subjects with motivation, and capable of engaging motivation to employ the technique, can use during and outside therapy to rebuild language function. Several ambient factors listed on the AOC, including Pre-stroke and Post-stroke Depression, Leisure Status, and Communication Partners and their Psychosocial Attributes, are likely to influence the extent to which generalization of skills beyond the clinical setting occurs. Thus, elements such as an individual's outlook, volitional involvement in activities, and support by family, friends, and society, could be essential in instantiating and sustaining extrinsic generalization as a part of the ambient experience.

Mechanistic generalization involves the training of a key brain resource, essential to language processing but not fundamentally linguistic, that enables improvement in language function. One such mechanism is intentional predisposition to use language, either in lieu of other communication techniques such as gesture, or in lieu of giving up on all attempts to communicate beyond the most basic of needs. Constraint-induced language therapy (CILT) attempts to develop intentional predisposition to use language by engaging subjects with aphasia in situations in which they must communicate and the only way to communicate effectively is verbally (Pulvermuller et al., 2001; Meinzer et al., 2005; Maher et al., 2006). Published studies of CILT have recruited other individuals with aphasia as partners in the therapy process. Recruitment in this process of Communication Partners listed on the checklist, specifically Spouses, Family, and Friends, could also serve to fuse therapeutic and ambient experience. In addition, ambient factors such as Age, Depression, Ethnic/Cultural Background, Socioeconomic Status, and Extent of Lesion, could be integral in the achievement of therapeutic outcomes.

Contextual generalization involves the acquisition of knowledge, predominantly contextual, during language therapy for aphasia, that aids retrieval of knowledge outside of therapy. In essence, the principle is that when individuals learn, the knowledge that is acquired includes not only the intended material but also knowledge about the context. This contextual knowledge may include attributes of other stimuli introduced during a treatment session. It may also include more general attributes of the situation, e.g., where the treatment was provided, characteristics of the treatment room and the therapist, who else was present, the mood of the participant, participant attitudes to the stroke experience and associated disability, and the strategies the participant brings to therapy. The greater the resemblance between context in the learning environment and context in the retrieval environment, the higher is the likelihood of success in knowledge retrieval. The nature of the ambient experience has a profound influence on the extent of commonality between it and the therapeutic experience. To maximize contextual generalization requires modifying therapeutic and ambient experiences to maximize commonality. Explicitly incorporating components of the retrieval environment, likely influenced by Socioeconomic Status, Ethnic/Cultural Background, and Leisure 


\begin{tabular}{|c|c|c|c|}
\hline Date & Patient Name & \multicolumn{2}{|l|}{ Tester Name } \\
\hline \multirow{2}{*}{$\begin{array}{l}\text { Ambient Factor } \\
\text { Intra-individual } \\
\text { Pre-stroke: }\end{array}$} & \multirow[t]{2}{*}{ Definition } & \multicolumn{2}{|c|}{ Check (+) OR (-) Below: } \\
\hline & & $\begin{array}{c}\text { Facilitator( } \\
\sqrt{ }\end{array}$ & $\underset{\sqrt{ }}{\text { Barrier(-) }}$ \\
\hline \multirow{2}{*}{ Gender } & Male $(+)$ & & \\
\hline & Female (-) & & \\
\hline \multirow{2}{*}{ Age } & 50 years old or younger $(+)$ & & \\
\hline & Older than 50 years old (-) & & \\
\hline \multirow{2}{*}{ Pre-stroke Depression } & No history of depression $(+)$ & & \\
\hline & History of depression $(-)$ & & \\
\hline \multirow{2}{*}{$\begin{array}{l}\text { Ethnic/Cultural } \\
\text { Background }\end{array}$} & Caucasian $(+)$ & & \\
\hline & Non-Caucasian (-) & & \\
\hline \multirow[b]{2}{*}{ Language(s) Spoken } & Primary language - other $(+)$ & & \\
\hline & $\begin{array}{l}\text { Primary language - English } \\
\text { or Chinese (-) }\end{array}$ & & \\
\hline \multirow{2}{*}{ Socioeconomic Status } & High SES(Educ/Income) $(+)$ & & \\
\hline & Low SES (Educ/Income) (-) & & \\
\hline \multicolumn{4}{|l|}{ Post-stroke: } \\
\hline \multirow{2}{*}{ Extent of Lesion } & Mild severity (+) & & \\
\hline & Moderate to severe (-) & & \\
\hline \multirow{2}{*}{ Depression } & No depression $(+)$ & & \\
\hline & Depression (-) & & \\
\hline \multirow{2}{*}{ Exercise } & Regular aerobic exercise $(+)$ & & \\
\hline & Limited aerobic exercise (-) & & \\
\hline \multicolumn{4}{|l|}{$\begin{array}{l}\text { Extra-individual } \\
\text { Personal Context: }\end{array}$} \\
\hline \multirow{2}{*}{ Leisure Status } & Active leisure life $(+)$ & & \\
\hline & Inactive leisure life (-) & & \\
\hline \multicolumn{4}{|l|}{ Social Context: } \\
\hline \multirow{2}{*}{$\begin{array}{l}\text { Communication Partners - } \\
\text { Spouses }\end{array}$} & Positive/married (+) & & \\
\hline & Negative/single (-) & & \\
\hline \multirow{2}{*}{$\begin{array}{l}\text { Communication Partners - } \\
\text { Family }\end{array}$} & High level family support $(+)$ & & \\
\hline & Low level family support (-) & & \\
\hline \multirow{2}{*}{$\begin{array}{l}\text { Communication Partners - } \\
\text { Psychosocial Attributes }\end{array}$} & Caregiver positive attitude $(+)$ & & \\
\hline & Caregiver negative attitude(-) & & \\
\hline \multirow{2}{*}{$\begin{array}{l}\text { Communication Partners - } \\
\text { Friends }\end{array}$} & Extensive social network $(+)$ & & \\
\hline & Limited social network (-) & & \\
\hline \multirow{2}{*}{$\begin{array}{l}\text { Communication Partners - } \\
\text { Society }\end{array}$} & Positive accommodation $(+)$ & & \\
\hline & Limited accommodation (-) & & \\
\hline \multicolumn{4}{|l|}{ Summary Remarks: } \\
\hline
\end{tabular}

FIGURE 2 | Ambient Influences on Outcome Checklist (AOC) McClung, Gonzalez Rothi, and Nadeau (2010). This Checklist has been developed as a guiding tool only. No attempt has been made to test its validity or reliability.

Status, into the treatment environment has the potential for fusing ambient and therapeutic experience with attendant benefits for communicative effectiveness.
Finally, Socially Mediated generalization involves changes in the perceptions of the subject and the subject's family regarding his/ her role in the family unit, the adoption of a new or revised role 
that subsumes more expectation of speech, more pressure to speak, and greater language production (Blonder, 2000). Socially Mediated generalization depends on explicit strategies for engineering the ambient experience, and would be instrumentally influenced by the Social Context enumerated in the AOC.

\section{DISCUSSION}

In summary, the authors have identified a considerable number of ambient experience factors relevant to aphasia recovery, but few have been adequately studied. The review is extensive, but not exhaustive. Literature outside the realm of aphasia-specific research has been examined to provide evidence in other related populations, but each factor may be potentially crucial for the neural and behavioral recovery of individuals with aphasia as well.

The authors wish to emphasize that the AOC clinical inventory tool is intended to serve as a guide for gathering relevant information to be considered by the clinician during the history-taking process. No attempt has been made to test its validity or reliability. It reflects the authors' interpretation of the current state of literature, and is meant to provide therapists with a greater cognizance of potent variables that may impact their patients' recovery beyond the clinic. In this regard, it is a work in progress, for it is hoped that future research will include testing it in the field and gathering empirical data to assess its validity and reliability. Until follow-up studies are implemented to address psychometric testing, clinicians

\section{REFERENCES}

Abrahams, B. S., Tentler, D., Perederiy, J. V., Oldham, M. C., Coppola, G., and Geschwind, D. H. (2007). Genomewide analyses of human perisylvian cerebral cortical patterning. Proc. Natl. Acad. Sci. U.S.A., 104, 17849-17854.

Adair, J. C., Nadeau, S. E., Conway, T. W., Gonzalez-Rothi, L. J., Heilman, P. C., Green, I. A., and Heilman, K. M. (2000). Alterations in the functional anatomy of reading induced by rehabilitation of an alexic patient. Neuropsychiatry Neuropsychol. Behav. Neurol. 13, 303-311.

Ahlsio, B., Britton, M., Murray, V., and Theorell, T. (1984). Disablement and quality of life after stroke. Stroke 15, 886-890.

Angeleri, F., Angeleri, V. A., Foschi, N., Giaquinto, S., and Nolfe, G. (1993). The influence of depression, social activity, and family stress on functional outcome after stroke. Stroke 24, 1478-1483.

Arai, Y., Sugiura, M., Washio, M., Miura, H., and Kudo, K. (2001). Caregiver depression predicts early discontinuation of care for disabled elderly at home. Psychiatry Clin. Neurosci. 55, 379-382.

Arango-Lasprilla, J. C., and Niemeier, J. (2007). Cultural issues in the rehabilitation of TBI survivors: recent research and new frontiers. J. Head Trauma Rehabil. 22, 73-74.
Arkin, S. M. (1999). Elder rehab: a student-supervised exercise program for Alzheimer's patients. Gerontologist39, 729-735.

Arkin, S. M. (2003). Student-led exercise sessions yield significant fitness gains for Alzheimer's patients. Am. J. Alzheimers Dis. Other Demen. 18, 159-170.

Barskova, T., and Wilz, G. (2007). Interdependence of stroke survivors' recovery and their relatives' attitudes and health: a contribution to investigating the causal effects. Disabil. Rehabil. 29, 1481-1491.

Basso, A., and Caporali,A. (2001).Aphasia therapy or the importance of being earnest. Aphasiology 15, 307-332.

Basso, A., Farabola, M., Grassi, M. P., and Laiacona, M. (1990). Aphasia in left-handers: comparison of aphasia profiles and language recovery in non-right-handed and matched right-handed patients. Brain Lang. 38, 233-252.

Bates, B., Choi, J. Y., Duncan, P. W., R. C., Lamberty, K., Reker, D., and Zorowitz, R. (2005). Veterans Affairs/ Department of Defense Clinical Practice guideline for the management of adult stroke rehabilitation care: executive summary. Stroke 36, 2049-2056.

Bates, E., Chen, S., Tzeng, O. J. L., Li, P., and Opie, M. (1991a). The noun-verb Glasberg, J. J., Graham, G. D., Katz,

are encouraged to use their best clinical judgment when implementing the AOC to assess the relative importance of each factor for each individual patient.

It is evident that numerous factors influence rehabilitation in individuals with aphasia. Functional independence and well-being are predicted by a combination of stroke severity, mental health, demographics, and economic variables (Ostwald et al., 2008). Thus, in order to provide the optimal therapeutic environment for these patients and to maximize their neural and functional recovery, all relevant influences - ambient and therapeutic - must be recognized. Finally, well-designed research examining the effects of potential ambient experiential factors on aphasia recovery that have not been adequately studied should, for those of us in the field of rehabilitation science and speech-language pathology, become a priority.

\section{ACKNOWLEDGMENTS}

The authors wish to thank Dr. Jay Rosenbek, Professor and Mentor, University of Florida College of Public Health and Health Professions, Rehabilitation Science and Communicative Disorders Departments, for his insight, inspiration, and support, as well as the Brain Rehabilitation Research Center, Malcom Randall DVA Medical Center, and McKnight Brain Institute for their resources. They also would like to acknowledge Dr. Leslie Gonzalez Rothi as the current recipient of the DVA Research Career Scientist Award and the University of Florida Bob Paul Family Endowed Chair in Neurology.

problem in Chinese aphasia. Brain Lang. 41, 203-233.

Bates, E., Wulfeck, B., and MacWhinney, B. (1991b). Cross-linguistic research in aphasia: an overview. Brain Lang. 41, 123-148.

Bennett, D. A., Schneider, J. A., Wilson, R. S., Bienias, J.L., and Arnold, S.E. (2005). Education modifies the association of amyloid but not tangles with cognitive function. Neurology 65, 953-955.

Bennett, D. A., Wilson, R. S., Schneider, J. A., Bienias, J. L., and Arnold, S. E. (2004). Cerebral infarctions and the relationship of depression symptoms to level of cognitive functioning in older persons. Am. J. Geriatr. Psychiatry 12, 211-219.

Blonder, L. X. (2000). "Language use," in Aphasia and Language: Theory to Practice, eds S. E. Nadeau, L. J. Rothi, and B. Crosson, (New York: Guilford Press), 284-295.

Bluvol, A., and Ford-Gilboe, M. (2004). Hope, health work and quality of life in families of stroke survivors. J. $A d v$. Nurs. 48, 322-332.

Boylstein, C., Rittman, M., Gubrium, J., Behrman, A., and Davis, S. (2005). The social organization in constraintinduced movement therapy. J. Rehabil. Res. Dev. 42, 263-275.

Bravata, D. M., Wells, C. K., Gulanski, B., Kernan, W. N., Brass, L. M., Long, J., and Concato, J. (2005). Racial disparities in stroke risk factors: the impact of socioeconomic status. Stroke 36, 1507-1511.

Braveman, P. A., Cubbin, C., Egerter, S., Chideya, S., Marchi, K. S., Metzler, M., and Posner, S. (2005). Socioeconomic status in health research: one size does not fit all. JAMA 294, 2879-2888.

Brosseau, L., Potvin, L., Philippe, P., and Boulanger, Y. L. (1996). Post-stroke inpatient rehabilitation. II. Predicting discharge disposition. Am. J. Phys. Med. Rehabil. 75, 431-436.

Brown, J. W., and Grober, E. (1983). Age, sex, and aphasia type. Evidence for a regional cerebral growth process underlying lateralization. J. Nerv. Ment. Dis. 171, 431-434.

Brown, K., McGahan, L., Alkhaledi, M., Seah, D., Howe, T., and Worrall, L. (2006). Environmental factors that influence the community participation of adults with aphasia: the perspective of service industry workers. Aphasiology 20, 595-615.

Brush, J.A. (2007). “Environmental interventions: improving communication and care in people with dementia," Paper presented at the meeting of the American Speech-Language Hearing Association Convention, Boston, MA, USA.

Burns, A., Blonder, L. X., and Heilman, K. M. (1991). Sociolinguistics and aphasia. J. Linguist. Anthropol. 1, 165-177.

Cameron, J. I., Cheung, A. M., Streiner, D. L., Coyte, P. C., and Stewart, D. E 
(2006). Stroke survivors' behavioral and psychologic symptoms are associated with informal caregivers' experiences of depression. Arch. Phys. Med. Rehabil. 87, 177-183.

Code, C. (2001). Multifactorial processes in recovery from aphasia: developing the foundations for a multileveled framework. Brain Lang. 77, 25-44.

Colcombe, S., and Kramer, A. F. (2003). Fitness effects on the cognitive function of older adults: a meta-analytic study. Psychol. Sci. 14, 125-130.

Colcombe, S. J., Erickson, K. I., Scalf, P. E., Kim, J. S., Prakash, R., McAuley, E., Elavsky, S., Marquez, D. X., Hu, L., and Kramer, A. F. (2006). Aerobic exercise training increases brain volume in aging humans. J. Gerontol. A Biol. Sci. Med. Sci. 61, 1166-1170.

Connor, L. T., Obler, L. K., Tocco, M., Fitzpatrick, P. M., and Albert, M. L. (2001). Effect of socioeconomic status on aphasia severity and recovery. Brain Lang. 78, 254-257.

Cox, A. M., McKevitt, C., Rudd, A. G., and Wolfe, C. D. (2006). Socioeconomic status and stroke. Lancet Neurol. 5, 181-188.

Cramer, S.C. (2008). Repairing the human brain after stroke: I. Mechanisms of spontaneous recovery. Ann. Neurol. 63, 272-287.

Crosson, B., Moore, A. B., Gopinath, K., White, K.D., Wierenga, C.E., Gaiefsky, M. E., Fabrizio, K. S., Peck, K. K., Soltysik, D., Milsted, C., Briggs, R. W., Conway, T. W., and Gonzalez Rothi, L. J. (2005). Role of the right and left hemispheres in recovery of function during treatment of intention in aphasia. J. Cogn. Neurosci. 17, 392-406.

Croteau, C., and LeDorze, G. (2001). Spouses' perceptions of persons with aphasia. Aphasiology 15, 811-825.

Cruice, M., Worrall, L., and Hickson, L. (2006). Quantifying aphasic people's social lives in the context of non-aphasic peers. Aphasiology 20, 1210-1225.

Cruice, M., Worrall, L., Hickson, L., and Murison, R. (2005). Measuring quality of life: comparing family members' and friends' ratings with those of their aphasic partners. Aphasiology 19, 111-129.

Dahlqvist, P., Ronnback, A., Risedal, A., Nergardh, R., Johansson, I. M., Seckl, J. R., Johansson, B. B., and Olsson, T. (2003). Effects of postischemic environment on transcription factor and serotonin receptor expression after permanent focal cortical ischemia in rats. Neuroscience 119, 643-652.

Davidson, B., Howe, T., Worrall, L., Hickson, L., and Togher, L. (2008). Social participation for older people with aphasia: the impact of commu- nication disability on friendships. Top. Stroke Rehabil. 15, 325-340.

de Riesthal, M., and Wertz, R. T. (2004). Prognosis for aphasia: relationship between selected biographical and behavioural variables and outcome and improvement. Aphasiology 18, 899-915.

DiCarlo, A., Lamassa, M., Baldereschi, M., Pracucci, G., Basile, A. M., Wolfe, C. D., Giroud, M., Rudd, A., Ghetti, A., Inzitari, D., and for the European BIOMED Study of Stroke Care Group. (2003). Sex differences in the clinical presentation, resource use, and 3-month outcome of acute stroke in Europe: data from a multicenter multinational hospital-based registry. Stroke 34, 1114-1119.

Duncan, P. W., Zorowitz, R., Bates, B., Choi, J. Y., Glasberg, J. J., Graham, G. D., Katz, R. C., Lamberty, K., and Reker, D. (2005). Management of adult stroke rehabilitation care: a clinical practice guideline. Stroke 36, e100-e143.

Ellison, C. G. (1991). Religious involvement and subjective well-being. $J$. Health Soc. Behav. 32, 80-99.

Elman, R. J. (2007). The importance of aphasia group treatment for rebuilding community and health. Top. Lang. Disord. 27, 300-308.

Eriksson, M., Asplund, K., Glader, E. L., Norrving, B., Stegmayr, B., Terent, A., Åsberg, K. H., and Wester, P.-O. (2004). Self-reported depression and use of antidepressants after stroke: a national survey. Stroke 35, 936-941.

Eslinger, P. J., Parkinson, K., and Shamay, S. G. (2002). Empathy and social-emotional factors in recovery from stroke. Curr. Opin. Neurol. 15, 91-97.

Evans, R. L., Matlock, A. L., Bishop, D. S., Stranahan, S., and Pederson, C. (1988). Family intervention after stroke: does counseling or education help? Stroke 19, 1243-1249.

Frame, M. W., Uphold, C. R., Shehan, C. L., and Reid, K. J. (2005). Effects of spirituality on health-related quality of life in men with HIV/AIDS: implications for counseling. Couns. Values 50, 5-19.

Garcia, L. J., Barrette, J., and Laroche, C. (2000). Perceptions of the obstacles to work reintegration for persons with aphasia. Aphasiology 14, 269-290.

Gargano, J. W., and Reeves, M. J. (2007). Sex differences in stroke recovery and stroke-specific quality of life: results from a statewide stroke registry. Stroke 38, 2541-2548.

Gargano, J. W., Wehner, S., and Reeves, M. (2008). Sex differences in acute stroke care in a statewide stroke registry. Stroke 39, 24-29.

Glader, E. L., Stegmayr, B., and Asplund, K. (2002). Poststroke fatigue: a 2-year follow-up study of stroke patients in Sweden. Stroke 33, 1327-1333.

Glader, E. L., Stegmayr, B., Norrving, B., Terent, A., Hulter-Asberg, K., Wester, P. O., and Asplund, K. (2003). Sex differences in management and outcome after stroke: a Swedish national perspective. Stroke 34, 1970-1975.

Glass, T. A., Matchar, D. B., Belyea, M., and Feussner, J. R. (1993). Impact of social support on outcome in first stroke. Stroke 24, 64-70.

Glosser, G., and Deser, T. (1991). Patterns of discourse production among neurological patients with fluent language disorders. Brain Lang. 40, 67-88.

Gonzalez-Torrecillas, J.L., Mendlewicz, J., and Lobo, A. (1995). Effects of early treatment of poststroke depression on neuropsychological rehabilitation. Int. Psychogeriatr. 7, 547-560.

Goodglass, H. (1993). Understanding Aphasia. San Diego: Academic Press.

Greenberger, H., and Litwin, H. (2003). Can burdened caregivers be effective facilitators of elder care-recipient health care? J. Adv. Nurs. 41, 332-341.

Hamm, R. J., Temple, M. D., O’Dell, D. M., Pike, B. R., and Lyeth, B. G. (1996) Exposure to environmental complexity promotes recovery of cognitive function after traumatic brain injury. J. Neurotrauma 13, 41-47.

Harrison, D. W., Beck, A. L., Vendemia, J. M., and Walters, R. P. (2003). Ambient sensory conditions: modification of receptive speech deficits in left-side stroke patients using bright light. Percept. Mot. Skills 96, 623-624.

Hartman-Maeir, A., Soroker, N., Ring, H., Avni, N., and Katz, N. (2007). Activities, participation and satisfaction one-year post stroke. Disabil. Rehabil. 29, 559-566.

Hilari, K., and Northcott, S. (2006). Social support in people with chronic aphasia. Aphasiology 20, 17-36.

Hochstenbach, J., Mulder, T., van Limbeek, J., Donders, R., and Schoonderwaldt, H. (1998). Cognitive decline following stroke: a comprehensive study of cognitive decline following stroke. J. Clin. Exp. Neuropsychol. 20, 503-517.

Hochstenbach, J. B., den Otter, R., and Mulder, T. W. (2003). Cognitive recovery after stroke: a 2-year follow-up. Arch. Phys. Med. Rehabil. 84, 1499-1504.

Holland, A. L., Greenhouse, J. B., Fromm, D., and Swindell, C. S. (1989). Predictors of language restitution following stroke: a multivariate analysis. J. Speech Hear. Res. 32, 232-238.

Holroyd-Leduc, J. M., Kapral, M. K., Austin, P. C., and Tu, J. V. (2000). Sex differences and similarities in the management and outcome of stroke patients. Stroke 31, 1833-1837.

Hopper, T., Holland, A., and Rewega, M. (2002). Conversational coaching: treatment outcomes and future directions. Aphasiology 16, 745-761.

Howe, T., Worrall, L., and Hickson, L. M. (2007). Observing people with aphasia: environmental factors that influence their community participation. Aphasiology 22, 6, 618-643.

Howe, T. J., Worrall, L. E., and Hickson, L. M.H. (2004). Review: what is an aphasia-friendly environment? Aphasiology 18, 1015-1037.

Idler, E. (1987). Religious involvement and the health of the elderly: some hypotheses and an initial test. Soc. Forces 66, 226-238.

Institute of Medicine (IOM). (2007). The Future of Disability in America. Washington, DC: The National Academies Press.

Jakovljevic, D., Sarti, C., Sivenius, J., Torppa, J., Mahonen, M., ImmonenRaiha, P., Kaarsalo, E., Alhainen, K., Tuomilehto, J., Puska, P., and Salomaa, V. (2001). Socioeconomic differences in the incidence, mortality and prognosis of intracerebral hemorrhage in Finnish adult population. The FINMONICA Stroke Register. Neuroepidemiology 20, 85-90.

Jeffreys, M. R. (2001). Evaluating enrichment program study groups: academic outcomes, psychological outcomes, and variables influencing retention. Nurse Educ. 26, 142-149.

Johansson, B. B. (2004). Functional and cellular effects of environmental enrichment after experimental brain infarcts. Restor. Neurol. Neurosci. 22, 163-174.

Johansson, B. B., and Ohlsson, A. L. (1996). Environment, social interaction, and physical activity as determinants of functional outcome after cerebral infarction in the rat. Exp. Neurol. 139, 322-327.

Jorgensen, H. S., Reith, J., Nakayama, H., Kammersgaard, L. P., Raaschou, H. O., and Olsen, T. S. (1999). What determines good recovery in patients with the most severe strokes? The Copenhagen Stroke Study. Stroke 30, 2008-2012.

Kagan, A., Black, S. E., Duchan, F. J., Simmons-Mackie, N., and Square, P. (2001). Training volunteers as conversation partners using "Supported Conversation for Adults with Aphasia" (SCA): a controlled trial. J. Speech Lang. Hear. Res. 44, 624-638.

Kapral, M. K., Fang, J., Hill, M. D., Silver, F., Richards, J., Jaigobin, C., and Cheung, A. M. (2005). Sex differences in stroke care and outcomes: results from the Registry of the Canadian Stroke Network. Stroke 36, 809-814. 
Kertesz, A., Harlock, W., and Coates, R. (1979). Computer tomographic localization, lesion size, and prognosis in aphasia and nonverbal impairment. Brain Lang. 8, 34-50.

Kimura, M., Robinson, R. G., and Kosier, J. T. (2000). Treatment of cognitive impairment after poststroke depression: a double-blind treatment trial. Stroke 31, 1482-1486.

King, R. B. (1996). Quality of life after stroke. Stroke 27, 1467-1472.

Kleim, J.A., Chan, S., Pringle, E., Schallert, K., Procaccio, V., Jimenez, R., and Cramer, S. C. (2006). BDNF val66met polymorphism is associated with modified experience-dependent plasticity in human motor cortex. Nat. Neurosci. 9, 735-737.

Kleim, J. A., and Jones, T. A. (2008). Principles of experience-dependent neural plasticity: implications for rehabilitation after brain damage. J. Speech Lang. Hear. Res. 51, S225-S239.

Kolb, B., Gibb, R., and Gorny, G. (2000). Cortical plasticity and the development of behavior after early frontal cortical injury. Dev. Neuropsychol. 18, 423-444.

Kwok, T., Lo, R. S., Wong, E., Wai-Kwong, T., Mok, V., and Kai-Sing, W. (2006). Quality of life of stroke survivors: a 1-year follow-up study. Arch. Phys. Med. Rehabil. 87, 1177-1182.

Lai, S. M., Duncan, P. W., Dew, P., and Keighley, J. (2005). Sex differences in stroke recovery. Prev. Chronic. Dis. 2, A13.

Lambon Ralph, M. A., and Ehsan, S. (2006). Age of acquisition effects depend on the mapping between representations and the frequency of occurrence: empirical and computational evidence. Vis. Cogn. 13, 928-948.

Lautenschlager, N. T., Cox, K. L., Flicker, L., Foster, J. K., van Bockxmeer, F. M., Xiao, J., Greenop, K. R., and Almeida, O. P. (2008). Effect of physical activity on cognitive function in older adults at risk for Alzheimer disease: a randomized trial. JAMA 300, 1077-1079.

Lazar, R. M., Speizer, A. E., Festa, J. R., Krakauer, J. W., and Marshall, R. S. (2007). Variability in language recovery after first-time stroke. $J$. Neurol. Neurosurg. Psychiatry 79, 5, 530-534.

Lendrem, W., and Lincoln, N. B. (1985). Spontaneous recovery of language in patients with aphasia between 4 and 34 weeks after stroke. J. Neurol. Neurosurg. Psychiatry 48, 743-748.

Levin, H. S. (2003). Neuroplasticity following non-penetrating traumatic brain injury. Brain Inj. 17, 665-674.

Lo, R. S., Cheng, J. O., Wong, E. M., Tang, W. K., Wong, L. K., Woo, J., and Kwok, T. (2008). Handicap and its determi- nants of change in stroke survivors: one-year follow-up study. Stroke 39, 148-153.

Lorenz, S. G. (2007). The potential of the patient room to promote healing and well-being in patients and nurses: an integrative review of the research. Holist. Nurs. Pract. 21, 263-277.

Low, J. T., Payne, S., and Roderick, P. (1999). The impact of stroke on informal carers: a literature review. Soc. Sci. Med. 49, 711-725.

Maher,L. M., Kendall, D., Swearengin, J.A., Rodriguez, A., Leon, S. A., Pingel, K., Holland, A., and Rothi, L. J. (2006). A pilot study of use-dependent learning in the context of constraint induced language therapy. J. Int. Neuropsychol. Soc. 12, 843-852.

Manzo, J. F., Blonder, L. X., and Burns, A. F. (1995). The social-interactional organisation of narrative and narrating among stroke patients and their spouses. Sociol. Health Illn. 17, 307-327.

Marks, B. L., Madden, D. J., Bucur, B., Provenzale, J. M., White, L. E., Cabeza, R., and Huettel, S. A. (2007). Role of aerobic fitness and aging on cerebral white matter integrity. Ann. N. Y.Acad. Sci. 1097, 171-174.

McKevitt, C., Redfern, J., Mold, F., and Wolfe, C. (2004). Qualitative studies of stroke: a systematic review. Stroke 35, 1499-1505.

Meijer, R., van Limbeek, J., Kriek, B., Ihnenfeldt, D., Vermeulen, M., and de, H. R. (2004). Prognostic social factors in the subacute phase after a stroke for the discharge destination from the hospital stroke-unit. A systematic review of the literature. Disabil. Rehabil. 26, 191-197.

Meijer, R., van Limbeek, J., Peusens, G., Rulkens, M., Dankoor, K., Vermeulen, M., and de Haan, R. J. (2005). The Stroke Unit Discharge Guideline, a prognostic framework for the discharge outcome from the hospital stroke unit. A prospective cohort study. Clin. Rehabil. 19, 770-778.

Meinzer, M., Djundja, D., Barthel, G., Elbert, T., and Rockstroh, B. (2005). Long-term stability of improved language functions in chronic aphasia after constraint-induced aphasia therapy. Stroke 36, 1462-1466.

Meinzer, M., Elbert, T., Wienbruch, C., Djundja,D.,Barthel, G., and Rockstroh, B. (2004). Intensive language training enhances brain plasticity in chronic aphasia. BMC Biol. 2, 20.

Melin, R., Fugl-Meyer, K. S., and FuglMeyer,A.R. (2003). Life satisfaction in 18- to 64-year-old Swedes: in relation to education, employment situation, health and physical activity. J. Rehabil. Med. 35, 84.

Milgram, N.W., Siwak-Tapp, C. T.,Araujo, J., and Head,E. (2006). Neuroprotective effects of cognitive enrichment. Ageing Res. Rev. 5, 354-369.

Milroy, L., and Perkins, L. (1992). Repair strategies in aphasic discourse: towards a collaborative model. Clin. Linguist. Phon. 6, 27-40.

Mimura, M., Kato, M., Kato, M., Sano, Y. Kojima, T., Naeser,M., and Kashima, H. (1998). Prospective and retrospective studies of recovery in aphasia: changes in cerebral blood flow and language functions. Brain 121, 2083-2094.

Moss, A., and Nicholas, M. (2006). Language rehabilitation in chronic aphasia and time postonset: a review of single-subject data. Stroke 37 , 3043-3051.

Nadeau, S. E., and Gonzalez-Rothi, L. J. (1993). Morphologic agrammatism following a right hemisphere stroke in a dextral patient. Brain Lang. 43 , 642-667.

Nadeau, S. E., Rothi, L. J. G., and Rosenbek, J. (2008). "Language rehabilitation from a neural perspective," in Language Intervention Strategies in Aphasia and Related Neurogenic Communication Disorders, 5th Edn., ed. R. Chapey (Philadelphia: Lippincott Williams and Wilkins), 689-734.

Nadeau, S. E., and Wu, S. S. (2006). CIMT as a behavioral engine in research on physiological adjuvants to neurorehabilitation: the challenge of merging animal and human research. NeuroRehabilitation 21, 107-130.

National Institutes of Health. (2008) Studies by Topic. ClinicalTrials.gov. Retrieved April 7, 2008, from http:// clinicaltrials.gov

National Institute on Deafness and Other Communication Disorders. (2009). Statistics on Voice, Speech, and Language. National Institute on Deafness and Other Communication Disorders. Retrieved March 1, 2010 from http://www.nidcd.nih.gov/ health/statistics

Neau, J. P., Ingrand, P., Mouille-Brachet, C., Rosier, M. P., Couderq, C., Alvarez, A., and Gil, R. (1998). Functional recovery and social outcome after cerebral infarction in young adults. Cerebrovasc. Dis. 8, 296-302.

Netz, Y., Tomer, R., Axelrad, S., Argov, E. and Inbar, O. (2007). The effect of a single aerobic training session on cognitive flexibility in late middle-aged adults. Int. J. Sports Med. 28, 82-87.

Niemi, M. L., Laaksonen, R., Kotila, M. and Waltimo, O. (1988). Quality of life 4 years after stroke. Stroke 19, 1101-1107.

Ostwald, S. K., Swank, P. R., and Khan, M. M. (2008). Predictors of functional independence and stress level of stroke survivors at discharge from inpatient rehabilitation. J. Cardiovasc. Nurs. 23 , 371-377.
Ouimet, M. A., Primeau, F., and Cole, M. G. (2001). Psychosocial risk factors in poststroke depression: a systematic review. Can. J. Psychiatry 46, 819-828.

Paolucci, S., Bragoni, M., Coiro, P., De Angelis, D., Fusco, F. R., Morelli, D., Venturiero, V., and Pratesi, L. (2006). Is sex a prognostic factor in stroke rehabilitation?: a matched comparison. Stroke 37, 2989-2994.

Parr, S., and Byng, S. (2000). "Perspectives and priorities: accessing users' views in functional communication assessment," in Neurogenic Communication Disorders: A Functional Approach, eds L. Worrall and C. Frattali (New York: Thieme), 55-66.

Parr, S., Byng, S., Gilpin, C., and Ireland, C. (1997). Talking About Aphasia: Living With Loss of Language After Stroke. Buckingham, UK: Open University Press.

Pedersen, P. M., Jorgensen, H. S., Nakayama, H., Raaschou, H. O., and Olsen, T. S. (1995). Aphasia in acute stroke: incidence, determinants, and recovery. Ann. Neurol. 38, 659-666.

Perkins, L. (1995). Applying conversation analysis to aphasia: clinical implications and analytic issues. Eur. J. Disord. Commun. 30, 372-383.

Perrin, P. B., Heesacker, M., Stidham, B. S., Rittman, M. R., and GonzalezRothi, L. J. (2008). Structural equation modeling of the relationship between caregiver psychosocial variables and functioning of individuals with stroke. Rehabil. Psychol. 53, 54-62.

Provinciali, L., and Coccia, M. (2002). Post-stroke and vascular depression: a critical review. Neurol. Sci. 22, 417-428.

Pulvermuller, F., Neininger, B., Elbert, T., Mohr, B., Rockstroh, B., Koebbel, P., and Taub, E. (2001). Constraintinduced therapy of chronic aphasia after stroke. Stroke 32, 1621-1626.

Ramasubbu, R., and Patten, S. B. (2003) Effect of depression on stroke morbidity and mortality. Can. J. Psychiatry 48, 250-257.

Raymer, A. M., Beeson, P., Holland, A. Kendall, D., Maher, L. M., Martin, N., Murray, L., Rose, M., Thompson, C. K., Turkstra, L.,Altmann, L., Boyle, M., Conway, T., Hula, W., Kearns, K., Rapp, B., Simmons-Mackie, N., and Rothi, L. J. G. (2008). Translational research in aphasia: from neuroscience to neurorehabilitation. J. Speech Lang. Hear. Res. 51, S259-S275.

Rayner, H., and Marshall, J. (2003). Training volunteers as conversation partners for people with aphasia. Int. J. Lang. Commun. Disord. 38, 149-164.

Redfern, J., McKevitt, C., and Wolfe, C. D. (2006). Development of 
complex interventions in stroke care: a systematic review. Stroke 37, 2410-2419.

Rijntjes, M. (2006). Mechanisms of recovery in stroke patients with hemiparesis or aphasia: new insights, old questions and the meaning of therapies. Curr. Opin. Neurol. 19, 76-83.

Risedal, A., Mattsson, B., Dahlqvist, P., Nordborg, C., Olsson, T., and Johansson, B. B. (2002).Environmental influences on functional outcome after a cortical infarct in the rat. Brain Res. Bull. 58, 315-321.

Robey, R. R. (1994). The efficacy of treatment for aphasic persons: a meta-analysis. Brain Lang. 47, 582-608.

Robey, R. R. (1998). A meta-analysis of clinical outcomes in the treatment of aphasia. J. Speech Lang. Hear. Res. 41, 172-187.

Robinson, R. G., Schultz, S. K., Castillo, C., Kopel, T., Kosier, J. T., Newman, R. M., Curdue, K., Petracca, G., and Starkstein, S. E. (2000). Nortriptyline versus fluoxetine in the treatment of depression and in short-term recovery after stroke: a placebo-controlled, double-blind study. Am. J. Psychiatry 157, 351-359.

Ross, K. B., and Wertz, R. T. (2001). Possible demographic influences on differentiating normal from aphasic performance. J. Commun. Disord. 34, 115-130.

Ross, K. B., and Wertz, R. T. (2003). Discriminative validity of selected measures for differentiating normal from aphasic performance. Am. J. Speech Lang. Pathol. 12, 312-319.

Sacchett, C., Byng, S., Marshall, J., and Pound, C. (1999). Drawing together: evaluation of a therapy programme for severe aphasia. Int. J. Lang. Commun. Disord. 34, 265-289.

Saltapidas, H., and Ponsford, J. (2007). The influence of cultural background on motivation for and participation in rehabilitation and outcome following traumatic brain injury. J. Head Trauma Rehabil. 22, 132-139.
Sarno, M. T. (1997). Quality of life in aphasia in the first post-stroke year. Aphasiology 11, 665-679.

Sarno, M. T., and Levita, E. (1979). Recovery in treated aphasia in the first year post-stroke. Stroke 10, 663-670.

Simmons-Mackie, N. N., Kagan, A., O’Neill Christie, C., Huijbregts, M., McEwen, S., and Willems, J. (2007). Communicative access and decision making for people with aphasia: implementing sustainable healthcare systems change. Aphasiology 21, 39-66.

Smith,A. (1971). Objective indices of severity of chronic aphasia in stroke patients. J. Speech Hear. Disord. 36, 167-207.

Stineman, M. G., and Granger, C. V. (1998). Outcome, efficiency, and timetrend pattern analyses for stroke rehabilitation. Am. J. Phys. Med. Rehabil. 77, 193-201.

Strauss, K. A., Puffenberger, E. G., Huentelman,M. J., Gottlieb, S., Dobrin, S. E., Parod, J. M., Stephan, D. A., and Morton, H. (2006). Recessive symptomatic focal epilepsy and mutant contactin-associated protein-like 2 . N. Engl. J. Med. 354, 1370-1377.

Sturm, J.W., Dewey, H.M., Donnan, G.A. Macdonell, R. A. L., McNeil, J. J., and Thrift, A. G. (2002). Handicap after stroke: how does it relate to disability, perception of recovery, and stroke subtype?: the North East Melbourne Stroke Incidence Study (NEMESIS). Stroke 33, 762-768.

Sveen, U., Thommessen, B., Bautz-Holter, E., Wyller, T. B., and Laake, K. (2004). Well-being and instrumental activities of daily living after stroke. Clin. Rehabil. 18, 267-274.

Thompson, H. J., McCormick, W. C., and Kagan, S. H. (2006). Traumatic brain injury in older adults: epidemiology, outcomes, and future implications. J. Am. Geriatr. Soc. 54, 1590-1595.

Threats, T. (2002). Evidence based practice research using the WHO frame- work. J. Med. Speech Lang. Pathol. 10, xvii-xxiv.

Tsouna-Hadjis, E., Vemmos, K. N., Zakopoulos, N., and Stamatelopoulos, S. (2000). First-stroke recovery process: the role of family social support. Arch. Phys. Med. Rehabil. 81, 881-887.

van den Bos, G. A., Smits, J. P., Westert, G. P., and van, S.A. (2002).Socioeconomic variations in the course of stroke: unequal health outcomes, equal care? J. Epidemiol. Community Health 56, 943-948.

Vernes, S. C., Newbury, D. F., Abrahams, B. S., Winchester, L., Nicod, J., Groszer, M., Alarcón, M., Oliver, P. L., Davies, K. E., Geschwind, D. H., Monaco, A.P., and Fisher, S. E. (2008). A functional genetic link between distinct developmental language disorders. N. Engl. J. Med. 359, 2337-2345.

Wehr, T. A., Rosenthal, N. E., and Sack, D. A. (1988). Environmental and behavioral influences on affective illness. Acta Psychiatr. Scand. Suppl. 341, 44-52.

Weir, N. U., Gunkel, A., McDowall, M., and Dennis, M. S. (2005). Study of the relationship between social deprivation and outcome after stroke. Stroke $36,815-819$.

Whitall, J. (2004). Stroke rehabilitation research: time to answer more specific questions? Neurorehabil. Neural Repair 18, 3-8.

Williams, C. L., Rittman, M. R., Boylstein, C., Faircloth, C., and Haijing, Q. (2005). Qualitative and quantitative measurement of depression in veterans recovering from stroke. J. Rehabil. Res. Dev. 42, 277-290.

Winter, B., Breitenstein, C., Mooren, F. C., Voelker, K., Fobker, M., Lechtermann, A., Krueger, K., Fromme, A., Korsukewitz, C., Floel, A., and Knecht, S. (2007). High impact running improves learning. Neurobiol. Learn. Mem. 87, 597-609.

Wood, W., Harris, S., Snider, M., and Patchel, S. A. (2005). Activity situa- tions on an Alzheimer's disease special care unit and resident environmental interactions, time use, and affect. $A m$. J. Alzheimers Dis. Other Demen. 20, 105-118.

World Health Organization (WHO). (2001). International Classification of Functioning, Disability, and Health. Geneva: WHO.

Worrall, L. (2006). Professionalism and functional outcomes. J. Commun. Disord. 39, 320-327.

Wulfeck, B., Bates, E., and Capasso, R. (1991). A crosslinguistic study of grammaticality judgments in Broca's aphasia. Brain Lang. 41, 311-336.

Zeisel, J., Silverstein, N. M., Hyde, J., Levkoff, S., Lawton, M. P., and Holmes, W. (2003). Environmental correlates to behavioral health outcomes in Alzheimer's special care units. Gerontologist 43, 697-711.

Zraick, R. I., and Boone, D. R. (1991). Spouse attitudes toward the person with aphasia. J. Speech Hear. Res. 34, 123-128.

Conflict of Interest Statement: The authors declare that the research was conducted in the absence of any commercial or financial relationships that could be construed as a potential conflict of interest.

Received: 24 March 2010; paper pending published: 23 June 2010; accepted: 07 September 2010; published online: 02 November 2010.

Citation: McClung JS, Gonzalez Rothi LJ and Nadeau SE (2010) Ambient experience in restitutive treatment of aphasia. Front. Hum. Neurosci. 4:183. doi: 10.3389/ fnhum.2010.00183

Copyright (๑) 2010 McClung, Gonzalez Rothi and Nadeau. This is an open-access article subject to an exclusive license agreement between the authors and the Frontiers Research Foundation, which permits unrestricted use, distribution, and reproduction in any medium, provided the original authors and source are credited. 